E3 Journal of Environmental Research and Management Vol. 8(2). pp. 018-039, June, 2017

Available online http://www.e3journals.org

ISSN 2141-7466 @ E3 Journals 2017

DOI : http://dx.doi.org/10.18685/EJERM(8)2_EJERM-17-012

Full Length Research Paper

\title{
Geoexchanger System for Buildings Heating and Cooling
}

\author{
Abdeen Mustafa Omer \\ Energy Research Institute (ERI), Nottingham, United Kingdom
}

Accepted 3 April, 2017

\begin{abstract}
Geothermal heat pumps (GSHPs), or direct expansion (DX) ground source heat pumps, are a highly efficient renewable energy technology, which uses the earth, groundwater or surface water as a heat source when operating in heating mode or as a heat sink when operating in a cooling mode. It is receiving increasing interest because of its potential to decrease primary energy consumption and thus reduce emissions of the greenhouse gases (GHGs). The main concept of this technology is that it uses the lower temperature of the ground (approximately $<32^{\circ} \mathrm{C}$ ), which remains relatively stable throughout the year, to provide space heating, cooling and domestic hot water inside the building area. The purpose of this study, however, is to examine the means of reducing of energy consumption in buildings, identifying GSHPs as an environmental friendly technology able to provide efficient utilisation of energy in the buildings sector, promoting the use of GSHPs applications as an optimum means of heating and cooling, and presenting typical applications and recent advances of the DX GSHPs. The study highlighted the potential energy saving that could be achieved through the use of ground energy sources. It also focused on the optimisation and improvement of the operation conditions of the heat cycle and performance of the DX GSHP. It is concluded that the direct expansion of the GSHP, combined with the ground heat exchanger in foundation piles and the seasonal thermal energy storage from solar thermal collectors, is extendable to more comprehensive applications.
\end{abstract}

Keywords: Geothermal heat pumps, direct expansion, ground heat exchanger, heating and cooling.

\section{INTRODUCTION}

The earth's surface acts as a huge solar collector, absorbing radiation from the sun. In the UK, the ground maintains a constant temperature of $11-13^{\circ} \mathrm{C}$ several metres below the surface all the year around (Fridleifsson, 2003). Among many other alternative energy resources and new potential technologies, the ground source heat pumps (GSHPs) are receiving increasing interest because of their potential to decrease primary energy consumption and thus reduce emissions of greenhouse gases (ASHRAE, 1995).

Direct expansion GSHPs are well suited to space heating and cooling and can produce significant reduction in carbon emissions. In the vast majority of systems, space cooling has not been normally considered, and this leaves ground-source heat pumps with some economic constraints, as they are not fully utilised throughout the year. The tools that are currently available for design of a GSHP system require the use of key site-specific parameters such as temperature gradient and the thermal and geotechnical properties of the local area. A main core with several channels will be able to handle heating and cooling simultaneously, provided that the channels are thermally insulated to some extent and can be operated independently as single units, but at the same time function as integral parts of the entire core. Loading of the core is done by diverting warm and cold air from the heat pump through the core during periods of excess capacity compared to the current needs of the building (Kalbus, et al., 2006; and Shah, 1991). The cold section of the core can also be loaded directly with air during the night, especially in spring and fall when nighttimes are cooler and daytimes are warmer. The shapes and numbers of the internal channels and the optimum configuration will obviously depend on the operating characteristics of each installation. Efficiency of a GSHP system is generally much greater than that of 
the conventional air-source heat pump systems. Higher COP (coefficient of performance) is achieved by a GSHP because the source/sink earth temperature is relatively constant compared to air temperatures. Additionally, heat is absorbed and rejected through water, which is a more desirable heat transfer medium due to its relatively high heat capacity.

The GSHPs in some homes also provide:

Radiant floor heating.

Heating tubes in roads or footbaths to melt snow in the winter.

Hot water for outside hot tubs and

Energy to heat hot water.

With the improvement of people's living standards and the development of economies, heat pumps have become widely used for air conditioning. The driver to this was that environmental problems associated with the use of refrigeration equipment, the ozone layer depletion and global warming are increasingly becoming the main concerns in developed and developing countries alike. With development and enlargement of the cities in cold regions, the conventional heating methods can severely pollute the environment. In order to clean the cities, the governments drew many measures to restrict citizen heating by burning coal and oil and encourage them to use electric or gas-burning heating. New approaches are being studied and solar-assisted reversible absorption heat pump for small power applications using waterammonia is under development (Ramshaw, 1995).

An air-source heat pump is convenient to use and so it is a better method for electric heating. The ambient temperature in winter is comparatively high in most regions, so heat pumps with high efficiency can satisfy their heating requirement. On the other hand, a conventional heat pump is unable to meet the heating requirement in severely cold regions anyway, because its heating capacity decreases rapidly when ambient temperature is below $-10^{\circ} \mathrm{C}$. According to the weather data in cold regions, the air-source heat pump for heating applications must operate for long times with high efficiency and reliability when ambient temperature is as low as $-15^{\circ} \mathrm{C}$ (Bergles, 1988). Hence, a great deal of research and development has been conducted to enable heat pumps to operate steadily with high efficiency and reliability in low temperature environments (Bowman, et al., 2001). For example, the burner of a room air conditioner, which uses kerosene, was developed to improve the performance in low outside temperature ( $\mathrm{Li}$, et al., 2004). Similarly, the packaged heat pump with variable frequency scroll compressor was developed to achieve high temperature air supply and high capacity even under the low ambient temperature of -10 to $-20^{\circ} \mathrm{C}$ (Mandelbrot, 1982). Such heat pump systems can be conveniently used for heating in cold regions. However, the importance of targeting the low capacity range is clear if one has in mind that the air conditioning units below $10 \mathrm{~kW}$ cooling account for more than $90 \%$ of the total number of units installed in the EU (Bejan, 2000).

\section{Methods and Laboratory Measurements}

This section describes the details of the prototype GSHP test rig, details of the construction and installation of the heat pump, heat exchanger, heat injection fan and water supply system. It also, presents a discussion of the experimental tests being carried out.

\section{Main Experimental Test Rig}

The schematic of the test rig that was used to support the two ground-loop heat exchangers is shown in Figure 1. It consisted of two main loops: heat source loop and evaporation heat pump. Three horeholes were drilled each 30 meters deep to provide sufficient energy. The closed-loop systems were laid and installed in a vertical well. The ground-loop heat exchangers were connected to the heat pump.

\section{Direct Expansion Heat Pump Installation}

The undertaken experimental work consists of three parts. The first step dealt with drilling three boreholes each 30 meter deep, digging out the pit and connection of the manifolds and preparation of coils. Holes were grouted with bentonite and sand. The pipes were laid and tested with nitrogen. Then, the pit was backfilled and the heat pump was installed. The second step was concerned with the setting up of the main experimental rig: construction and installation of the heat injection fan, water pump, expansion valve, flow meter, electricity supply, heat exchanger and heat pump. The third step was an installation of refrigerator and measurements.

The aim of this project is to present and develop a GSHP system to provide heating and cooling for buildings (Figure 2). The heat source loop consisted of two earth loops: one for vapour and one for liquid. A refrigeration application is only concerned with the low temperature effect produced at the evaporator; while a heat pump is also concerned with the heating effect produced at the condenser.

The earth-energy systems, EESs, have two parts; a circuit of underground piping outside the house, and a heat pump unit inside the house. And unlike the airsource heat pump, where one heat exchanger (and frequently a compressor) is located outside, the entire GSHP unit for the EES is located inside the house.

The outdoor piping system can be either an open system or closed loop. An open system takes advantage 


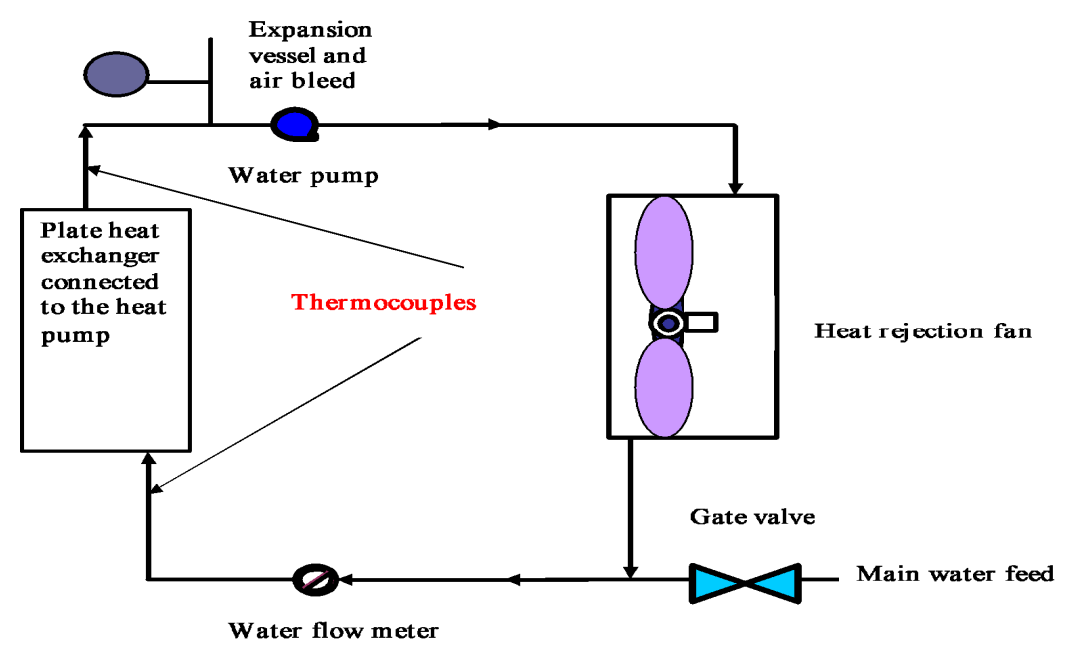

Figure 1: Sketch of installing a heat pump.

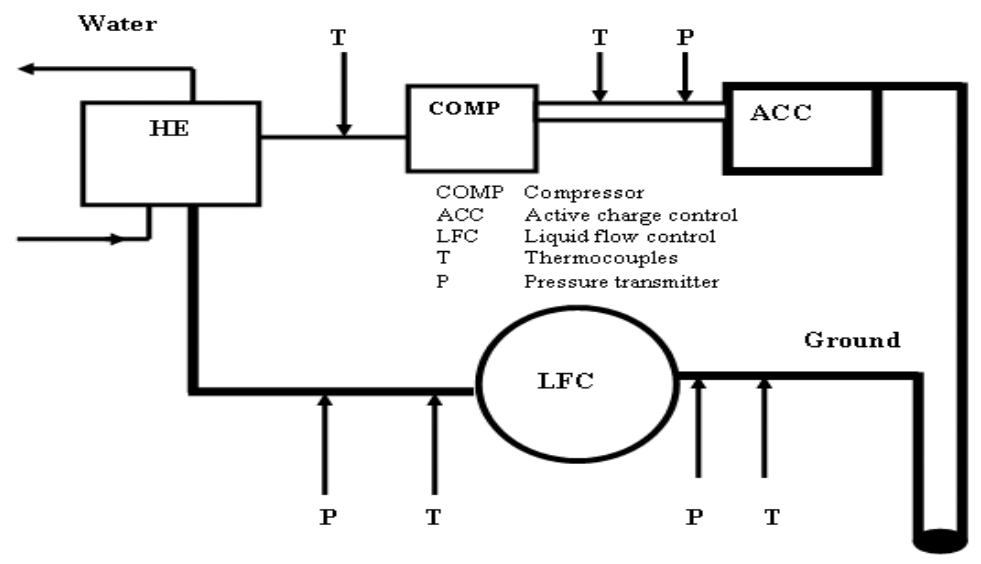

Figure 2: Ground loops connections to heat pump and heat exchanger.

of the heat retained in an underground body of water. The water is drawn up through a well directly to the heat exchanger, where its heat is extracted. The water is discharged either to an aboveground body of water, such as a stream or pond, or back to the underground water body through a separate well. Closed-loop systems, on the other hand, collect heat from the ground by means of a continuous loop of piping buried underground. An antifreeze solution (or refrigerant in the case of a DX earth-energy system), which has been chilled by the heat pump's refrigeration system to several degrees colder than the outside soil, and circulates through the piping, absorbing heat from the surrounding soil.

The direct expansion (DX) GSHP installed for this study was designed taking into account the local meteorological and geological conditions. The site was at the School of the Built Environment, University of Nottingham, where the demonstration and performance monitoring efforts were undertaken Figures (3-4). The heat pump has been fitted and monitored for a one-year period. The study involved the development of a design and simulation tool for modelling the performance of the cooling system, which acts as a supplemental heat rejecting system using a closed-loop GSHP system. With the help of the Jackson Refrigeration (Refrigeration and Air Conditioning engineers) the following tasks were carried out:

Connection of the ground loops to the heat pump Connection of the heat pump to the heat exchanger Vacuum on the system

Charging the refrigeration loop with $\mathrm{R} 407 \mathrm{C}$ refrigerant

\section{Water Supply System}

The water supply system consisted of a water pump, boiler, water tank, expansion and valve flow meter (Figure 4). A thermostatically controlled water heater supplied warm water, which was circulated between the warm water supply tank and warm water storage tank using a pump to keep the surface temperature of the trenches at a desired level. 

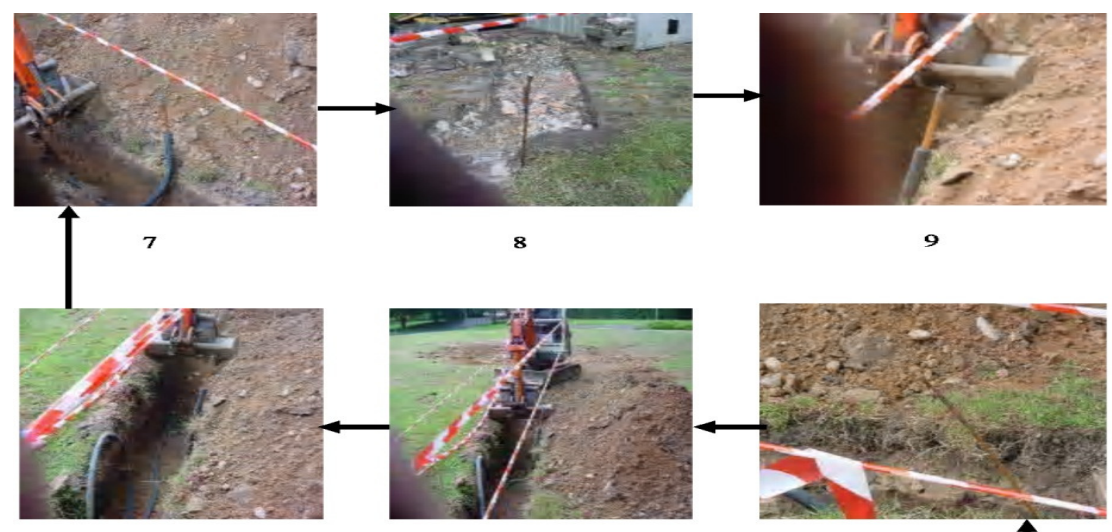

9

6
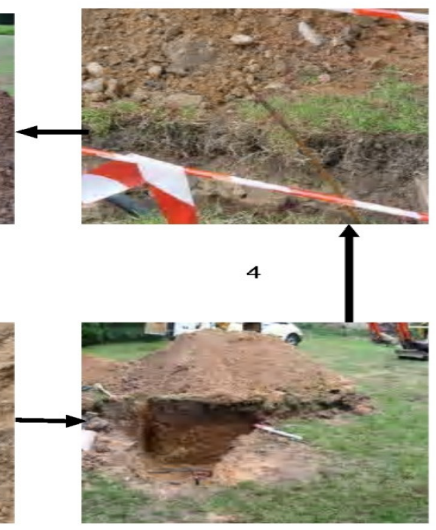

2

Figure 3. Drilling (1-2) digging of the pit (3), connection of the manifolds (4), grouting, preparation of the coils (5-6) and the source loop, which consists of two earth loops: one for vapour and one for liquid (7-9).

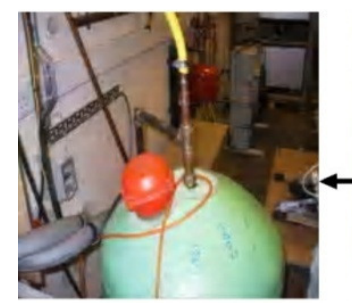

9
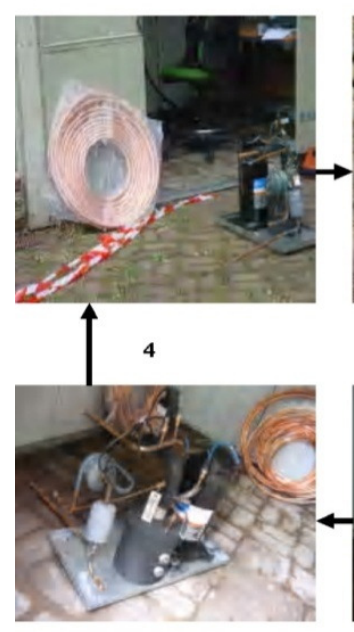

3

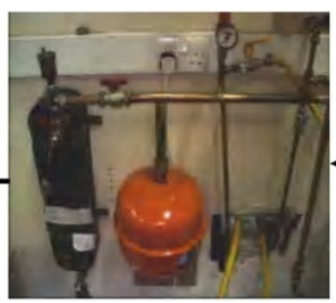

8

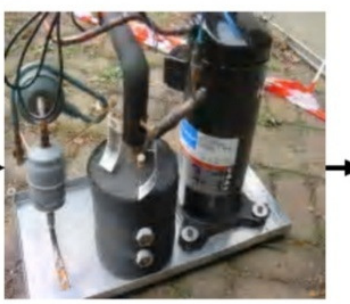

5

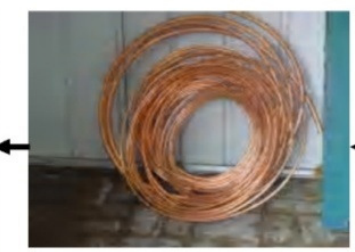

2
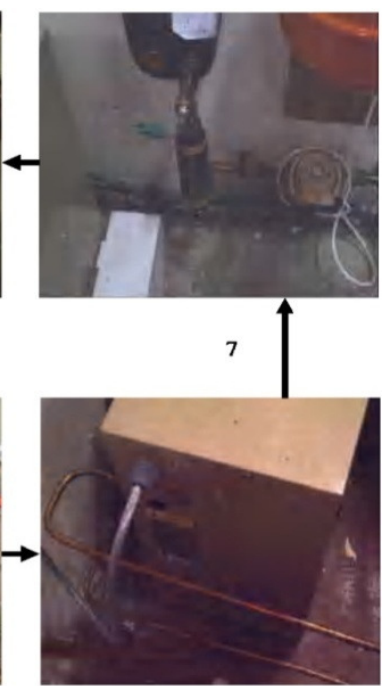

6

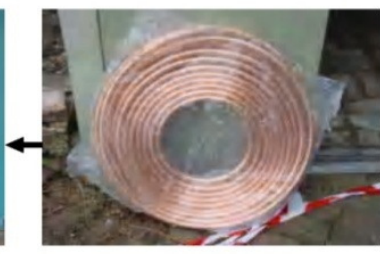

Figure 4: Preparation of coils (1-2), installation of heat pump (3-6) and connection of water supply system (water pump, flow meter, expansion valve and the boiler) (7-9). 
The ground source heat pump system, which uses a ground source with a smaller annual temperature variation for heating and cooling systems, has increasingly attracted market attention due to lower expenses to mine for installing underground heat absorption pipes and lower costs of dedicated heat pumps, supported by environmentally oriented policies. The theme undertakes an evaluation of heat absorption properties in the soil and carries out a performance test for a DX heat pump and a simulated operation test for the system. In fact, these policies are necessary for identifying operational performance suitable for heating and cooling, in order to obtain technical data on the heat pump system for its dissemination and maintain the system in an effort of electrification.

In these circumstances, the study estimated the heat properties of the soil in the city of Nottingham and measured the thermal conductivity for the soil at some points in this city, aimed at identifying applicable areas for ground source heat pump system.

\section{Design and Installation}

Installation of the heat pump system and especially the ground heat exchanger needs to be carefully programmed so that it does not interfere with or delay any other construction activities. The time for installation depends on soil conditions, length of pipe, equipment required and weather conditions. The DX systems are most suitable for smaller domestic applications.

The most important first step in the design of a GSHP installation is accurate calculation of the building's heat loss, its related energy consumption profile and the domestic hot water requirements. This will allow accurate sizing of the heat pump system. This is particularly important because the capital cost of a GSHP system is generally higher than for alternative conventional systems and economies of scale are more limited. Oversizing will significantly increase the installed cost for little operational saving and will mean that the period of operation under part load is increased. Frequent cycling reduces equipment life and operating efficiency. Conversely if the system is undersized design conditions may not be met and the use of top-up heating, usually direct acting electric heating, will reduce the overall system efficiency. In order to determine the length of heat exchanger the piping material is needed. The piping material used affects the life; maintenance costs, pumping energy, capital cost and heat pump performance.

\section{Heat Pump Performance}

The need for alternative low-cost energy resources has given rise to the development of the DX-GSHPs for space cooling and heating. The performance of the heat pump depends on the performance of the ground loop and vice versa. It is therefore essential to design them together. Closed-loop GSHP systems will not normally require permissions/authorisations from the environment agencies. However, the agency can provide comment on proposed schemes with a view to reducing the risk of groundwater pollution or derogation that might result. The main concerns are:

$>$ Risk of the underground pipes/boreholes creating undesirable hydraulic connections between different water bearing strata.

$>$ Undesirable temperature changes in the aquifer that may result from the operation of a GSHP.

$>$ Pollution of groundwater that might occur from leakage of additive chemicals used in the system. Efficiencies for the GSHPs can be high because the ground maintains a relatively stable temperature allowing the heat pump to operate close to its optimal design point. Efficiencies are inherently higher than for air source heat pumps because the air temperature varies both throughout the day and seasonally such that air temperatures, and therefore efficiencies, are lowest at times of peak heating demand.

A heat pump is a device for removing heat from one place - the 'source' and transferring it at a higher temperature to another place. The heat pumps consist of a compressor, a pressure release valve, a circuit containing fluid (refrigerant), and a pump to drive the fluid around the circuit. When the fluid passes through the compressor it increases in temperature. This heat is then given off by the circuit while the pressure is maintained. When the fluid passes through the relief valve the rapid drop in pressure results in the cooling of the fluid.

The fluid then absorbs heat from the surroundings before being re-compressed. In the case of domestic heating the pressurised circuit provides the heating within the dwelling. The depressurised component is external and, in the case of ground source heat pumps, is buried in the ground. Heat pump efficiencies improve as the temperature differential between 'source' and demand temperature decreases, and when the system can be 'optimised' for a particular situation. The relatively stable ground temperatures moderate the differential at times of peak heat demand and provide a good basis for optimisation.

The refrigerant circulated directly through the ground heat exchanger in a direct expansion (DX) system but most commonly GSHPs are indirect systems, where a water/antifreeze solution circulates through the ground loop and energy is transferred to or from the heat pump refrigerant circuit via a heat exchanger. This application will only consider closed loop systems. The provision of cooling, however, will result in increased energy consumption. The GSHPs are particularly suitable for new build as the technology is most efficient when used to supply low temperature distribution systems such as 


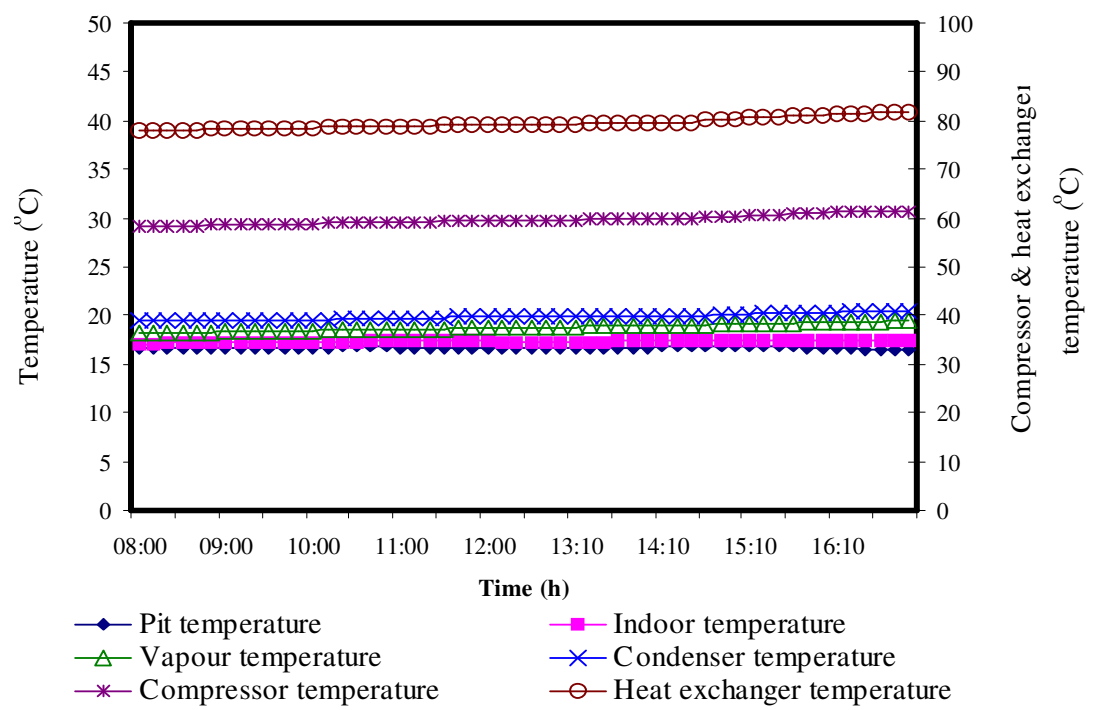

Figure 5: Variation of temperatures per day for the DX system.

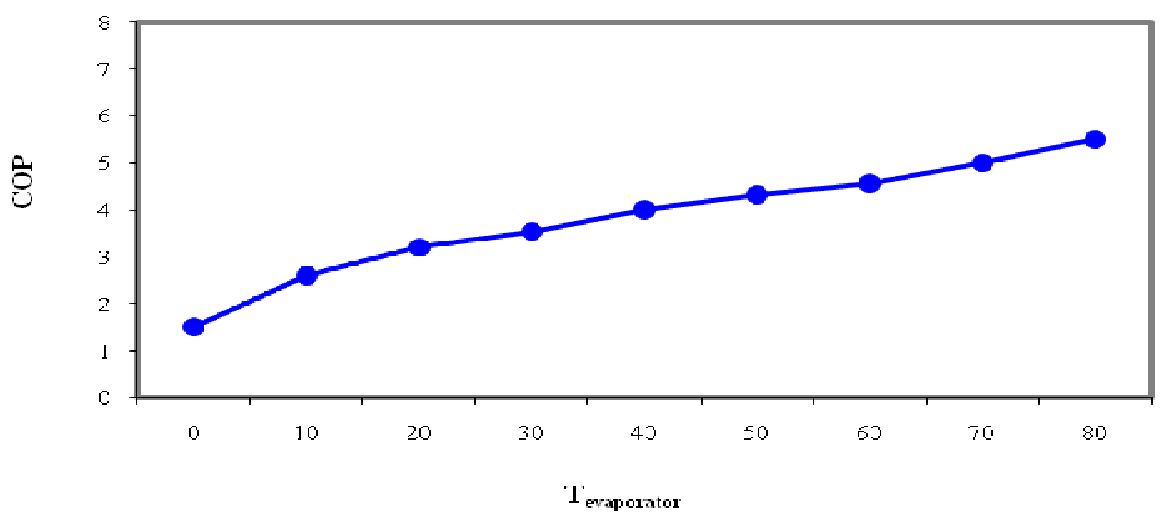

Figure 6. Heat pump performance vs evaporation temperature.

underfloor heating. They can also be used for retrofit especially in conjunction with measures to reduce heat demand. They can be particularly cost effective in areas where gas mains are not available or for developments where there is an advantage in simplifying the infrastructure provided.

\section{Coefficient of Performance (COP)}

Heat pump technology can be used for heating only, or for cooling only, or be 'reversible' and used for heating and cooling depending on the demand. Reversible heat pumps generally have lower COPs than heating only heat pumps. They will, therefore, result in higher running costs and emissions. Several tools are available to measure heat pump performance. The heat delivered by the heat pump is theoretically the sum of the heat extracted from the heat source and the energy needed to deliver the cycle. Figure 5 shows the variations of temperature with the system operation hours. Several tools are available to measure heat pump performance. The heat delivered by the heat pump is theoretically the sum of the heat extracted from the heat source and the energy needed to derive the cycle. For electrically driven heat pumps the steady state performance at a given set of temperatures is referred to as the coefficient pf performance (COP). It is defined as the ration of the heat delivered by the heat pump and the electricity supplied to the compressor: $\mathrm{COP}=$ [heat output $\left.\left(\mathrm{kW}_{\mathrm{th}}\right)\right] /$ [electricity input $\left(\mathrm{kW}_{\mathrm{el}}\right)$ ] (1)

For an ideal heat pump the COP is determined solely by the condensation temperature and the temperature lift: $\mathrm{COP}=\left[\right.$ condensing temperature $\left.\left({ }^{\circ} \mathrm{C}\right)\right] /[$ temperature lift $\left.\left({ }^{\circ} \mathrm{C}\right)\right]$

Figure 6 shows the heat pump COP as a function of the evaporation temperature. Figure 7 shows the heat pump COP as a function of the condensation temperature. As can be seen, the theoretically efficiency is strongly dependent on the temperature lift (compressed). It is 


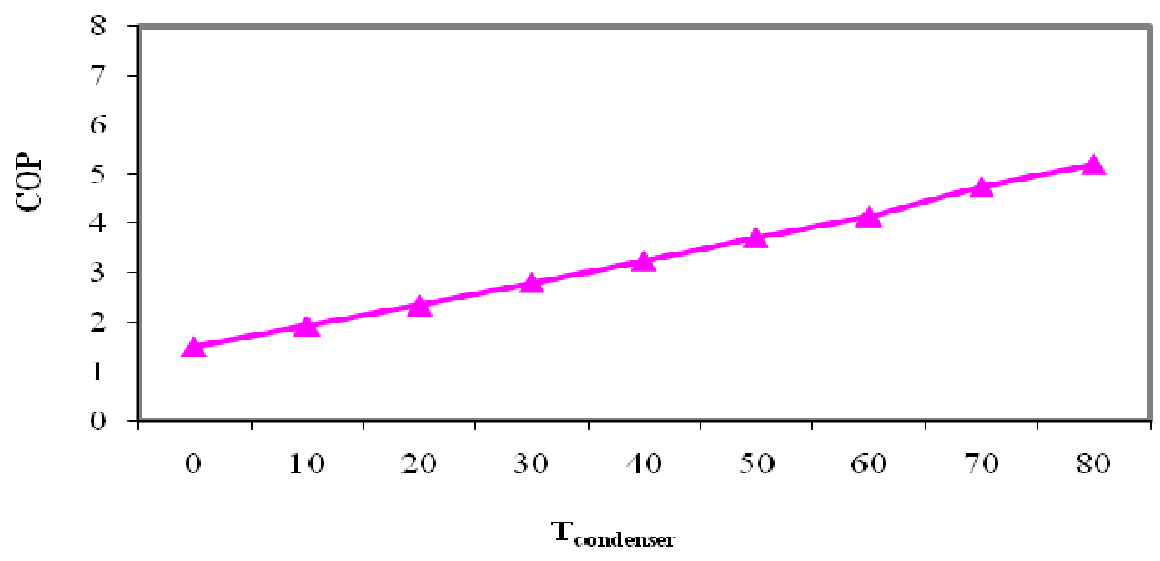

Figure 7. Heat pump performance vs condensation temperature.

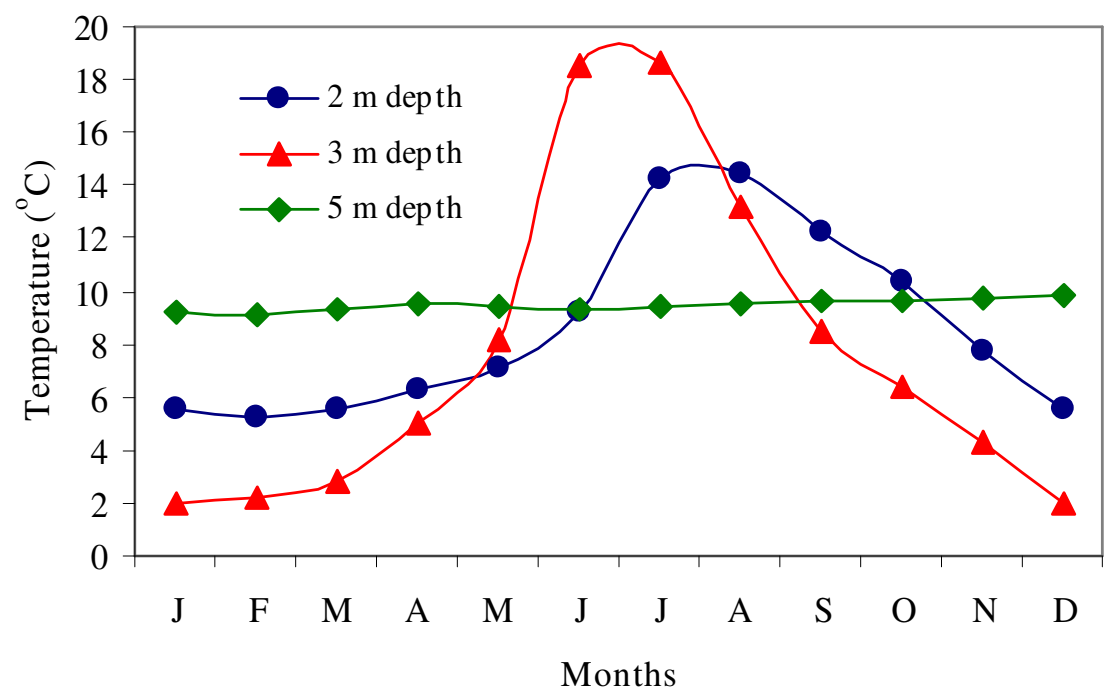

Figure 8. Seasonal temperature variations.

important not only to have as high a source temperature as possible but also to keep the sink temperature (i.e., heating distribution temperature) as low as possible. The achievable heat pump efficiency is lower than the ideal efficiency because of losses during the transportation of heat from the source to the evaporator and from the condenser to the room and the compressor. Technological developments are steadily improving the performance of the heat pumps.

The need for alternative low-cost energy has given rise to the development of the GSHP systems for space cooling and heating in residential and commercial buildings. The GSHP systems work with the environment to provide clean, efficient and energy-saving heating and cooling the year round. The GSHP systems use less energy than alternative heating and cooling systems, helping to conserve the natural resources. The GSHP systems do not need large cooling towers and their running costs are lower than conventional heating and air-conditioning systems. As a result, GSHP systems have increasingly been used for building heating and cooling with an annual rate of increase of $10 \%$ in recent years. While in some zones such as hot summer and cold winter areas, there is a major difference between heating load in winter and cooling load in summer. Thus the soil temperature increases gradually after yearly operation of the GSHP system because of the inefficient recovery of soil temperature as the result of imbalance loads (Figure 8). Finally, the increase of soil temperature will decrease the COP of the system.

The first law of thermodynamics is often called the law of conservation of energy. Based on the first law or the law of conservation of energy for any system, open or closed, there is an energy balance as:

[Net amount of energy added to system] = [Net increase of stored energy in system] 
Table 1: Measured and computed thermodynamic properties of R-22

\begin{tabular}{cccccc}
\hline \multicolumn{3}{c}{ Measured } & \multicolumn{3}{c}{ Computed } \\
\hline State & $\begin{array}{c}\text { Pressure } \\
(\mathbf{k P a})\end{array}$ & $\begin{array}{c}\text { Temperature } \\
\left({ }^{\circ} \mathbf{C}\right)\end{array}$ & $\begin{array}{c}\text { Specific } \\
\text { enthalpy } \\
(\mathbf{k J} / \mathbf{k g})\end{array}$ & $\begin{array}{c}\text { Specific } \\
\text { entropy } \\
\left(\mathbf{k J} / \mathbf{k g}{ }^{\circ} \mathbf{K}\right)\end{array}$ & $\begin{array}{c}\text { Specific } \\
\text { volume } \\
\left(\mathbf{m}^{\mathbf{3}} / \mathbf{k g}\right)\end{array}$ \\
\hline 1 & 310 & -10 & 402.08 & 1.78 & 0.075 \\
2 & 304 & -4 & 406.25 & 1.79 & 0.079 \\
3 & 1450 & 82 & 454.20 & 1.81 & 0.021 \\
4 & 1435 & 70 & 444.31 & 1.78 & 0.019 \\
5 & 1410 & 34 & 241.40 & 1.14 & 0.0008 \\
6 & 1405 & 33 & 240.13 & 1.13 & 0.0008 \\
7 & 320 & -12.8 & 240.13 & 1.15 & 0.0191 \\
\hline
\end{tabular}

[Energy in] - [Energy out $]=[$ Increased of stored energy in system] (4)

In a cycle, the work reduction of produced by a power cycle (or the increase in work required by a refrigeration cycle) equals the absolute ambient temperature multiplied by the sum of irreversibilities in all processes in the cycle. Thus, the difference in reversible and actual work for any refrigeration cycle, theoretical or real, operating under the same conditions becomes:

$\mathrm{W}_{\text {actual }}=\mathrm{W}_{\text {reversible }}+\mathrm{T}_{\mathrm{o}} \sum \mathrm{I}$

$W_{\text {actual }}=W_{\text {reversible }}+T_{0} \sum I$

\section{Where:}

$\mathrm{I}$ is the irreversibility rate, $\mathrm{kW} / \mathrm{K}$.

$\mathrm{T}_{\mathrm{o}}$ is the absolute ambient temperature, $\mathrm{K}$

Refrigeration cycles transfer thermal energy from a region of low temperature to one of higher temperature. Usually the higher temperature heat sink is the ambient air or cooling water, at temperature $T_{0}$, the temperature of the surroundings. A refrigeration cycle performance of is usually described by a coefficient of performance (COP), defined as the benefit of the cycle (amount of heat removed) divided by the required energy input to operate the cycle:

$\mathrm{COP}=[$ Useful refrigeration effect $] /$

[Net energy supplied from external sources]

For a mechanical vapour compression system, the net energy supplied is usually in the form of work, mechanical or electrical and may include work to the compressor and fans or pumps. Thus,

$\mathrm{COP}=\left[\mathrm{Q}_{\text {evap }}\right] /\left[\mathrm{W}_{\text {net }}\right]$

In an absorption refrigeration cycle, the supplied net energy is usually in the form of heat into the generator and work into the pumps and fans, or:

$\mathrm{COP}=\left(\mathrm{Q}_{\text {evap }}\right) /\left(\mathrm{Q}_{\text {gen }}+\mathrm{W}_{\text {net }}\right)$

In many cases, the work supplied to an absorption system is very small compared to the amount of heat supplied to the generator, so the work term is often neglected. Applying the second thermodynamic to an entire refrigeration cycle shows that a completely reversible cycle operating under the same conditions has the maximum possible COP. Table 1 lists the measured and computed thermodynamic properties of the refrigerant. Departure of the actual cycle from an ideal reversible cycle is given by the refrigerating efficiency:

$\eta_{\mathrm{R}}=\mathrm{COP} /(\mathrm{COP})_{\mathrm{rev}}$

\section{Seasonal Performance Factor (SPF)}

There are two primary factors to describe the efficiency of heat pumps. First, the coefficient pf performance (COP) is determined in the test stand with standard conditions for a certain operating point and/or for a number of typical operating points. Second, the seasonal performance factor (SPF), describes the efficiency of the heat pump system under real conditions during a certain period, for example for one year. The SPFs in this case are the ratio of the heat energy produced by the heat pump and the back-up heater and the corresponding energy required of the heat pump. The SPF for individual months and an average value for the year 2008 for the DX GSHP are shown in Figure 9. The assessment of the 2008 measurement data for the GSHP in the buildings providing both heating and cooling reveals a seasonal performance factor (SPF) of 3.8. The SPF of the individual system was in the range of 3.0-4.6.

The preliminary results show that the GSHPs are especially promising when it comes to reaching high efficiencies under real conditions. However, there is still a need for optimisation in the integration of the unit in the supply system for the house and for the control strategies of the heat pump. Thus, a poorly integrated heat source or an incorrectly designed heat sink can decrease the seasonal performance factor of the heat pump.The main point to consider is the careful layout of the system as a whole, rather than with respect to single components. High installation costs have been identified as a major barrier to wider application of the GSHPs often referred to as geothermal heat pumps. The primary reason cited for higher cost is the ground loop. Other factors may be high costs of the GSHP heat pump units and supplies, interior installation, and limited competition. The ground-source machine had lower demand (summer and winter) and 




Figure 9: Seasonal performance for individual months and average for 2008.

lower heating energy use than either of the air heat pumps. Comparisons with natural gas must be based on cost since the units for natural gas (therm $=100,000 \mathrm{Btu}$ ) are different from those of electrical energy unit (kWh).

\section{Comparison of Numerical Simulation and Experiments}

The GSHPs are generally more expensive to develop, however they have very low operating costs, therefore, it is necessary to have an idea of the energy use and demand of these equipments. The performances are normally rated at a single fluid temperature $\left(0^{\circ} \mathrm{C}\right)$ for heating COP and a second for cooling EER $\left(25^{\circ} \mathrm{C}\right)$. These ratings reflect temperatures for an assumed location and ground heat exchanger type, and are not ideal indicators of energy use. This problem is compounded by the nature of ratings for conventional equipment. The complexity and many assumptions used in the procedures to calculate the seasonal efficiency for air-conditioners, furnaces, and heat pumps (SEER, AFUE, and HSPF) make it difficult to compare energy use with equipment rated under different standards. The accuracy of the results is highly uncertain, even when corrected for regional weather patterns. These values are not indicators for demand since they are seasonal averages and performance at severe conditions is not heavily weighted.

The American Society of Heating, Refrigerating, and Air-Conditioning Engineers (ASHRAE) (Luo, et al., 2005) recommends a weather driven energy calculation, like the bin method, in preference to single measure methods like seasonal energy efficiency ratio (SEER), seasonal performance factor (SPF), energy efficiency rating (EER), coefficient of performance (COP annual fuel utilisation efficiency rating (AFUE), and heating season performance factor (HSPF).
The bin method permits the energy use to be calculated based on local weather data and equipment performance over a wide range of temperatures (Luo, et al., 2007). Both solid and liquid parts co-existed in one control volume of non-isothermal groundwater flow. It was therefore necessary to integrate the two parts into one energy equation. Accordingly, the governing equation (Luo, et al., 2007) describing non-isothermal groundwater flow in a saturated porous medium was as follows:

$$
\begin{aligned}
& \mathrm{T}(\Delta \mathrm{v})+(\delta \mathrm{T} / \delta \mathrm{t}) \quad \sigma=\mathrm{a}_{\mathrm{t}} \Delta^{2} \mathrm{~T}+\mathrm{qt} /\left(\rho \mathrm{C}_{\mathrm{p}}\right)_{\mathrm{f}} \\
& \text { (10) } \\
& \left(\rho C_{p}\right)_{t}=\psi\left(\rho C_{p}\right)_{t}+(1-\quad \psi) \quad\left(\rho C_{p}\right)_{s} \\
& \text { (11) }
\end{aligned}
$$

Latent heat during phase changes between freezing soil and thawing soil was regarded as an inner heat source described as follows:

$\mathrm{WH} \quad\left(\sigma_{\mathrm{d}}\right) \quad \delta \mathrm{f}_{\mathrm{s}} / \delta \mathrm{t}_{\mathrm{s}} \quad=\quad \mathrm{q}_{\mathrm{s}}$

(12)

$(\delta \mathrm{T} / \delta \mathrm{t}) \sigma+\mathrm{U}_{\mathrm{x}} \delta \mathrm{T}_{\mathrm{f}} / \delta \mathrm{x}=\mathrm{\alpha}_{\mathrm{t}} \Delta^{2} \mathrm{~T}+\mathrm{qt} /\left(\rho \mathrm{C}_{\mathrm{p}}\right)_{\mathrm{f}}$ (13)

Where:

$\mathrm{C}_{\mathrm{p}} \quad$ is the specific heat $\left(\mathrm{J} \mathrm{kg}^{-1} \mathrm{~K}^{-1}\right)$; $\mathrm{q}$ is the internal heat source $\left(\mathrm{Wm}^{-3}\right)$.

$\mathrm{W}$ is the water content in soil (\%); $\mathrm{T}$ is the temperature $\left({ }^{\circ} \mathrm{C}\right)$.

$\mathrm{H} \quad$ is the condensation latent heat of water $\left(\mathrm{J} \mathrm{kg}^{-1}\right)$.

$\mathrm{t} \quad$ is the times (s); $\mathrm{U}$ is the velocity $\left(\mathrm{ms}^{-1}\right)$.

$f_{s} \quad$ is the solid phase ratio.

$s \quad$ is the soil; $f$ is the groundwater.

$\Psi \quad$ is the porosity.

$\alpha \quad$ is the convective heat transfer coefficient $\left(\mathrm{Wm}^{-2} \mathrm{~K}\right.$ 


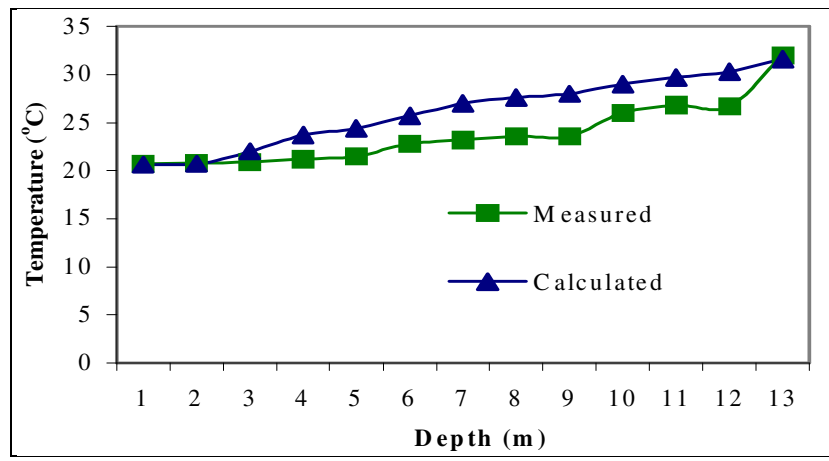

Figure 11: Comparison of calculations and experiments for saturated soil without groundwater flow (SS).

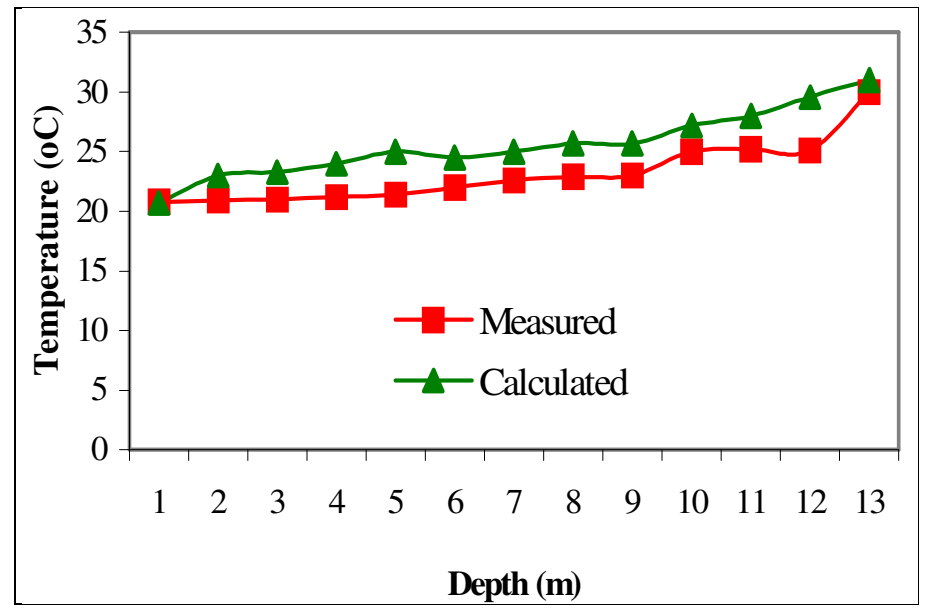

Figure 12: Comparison of calculations and experiments for unsaturated soil without groundwater flow (US).

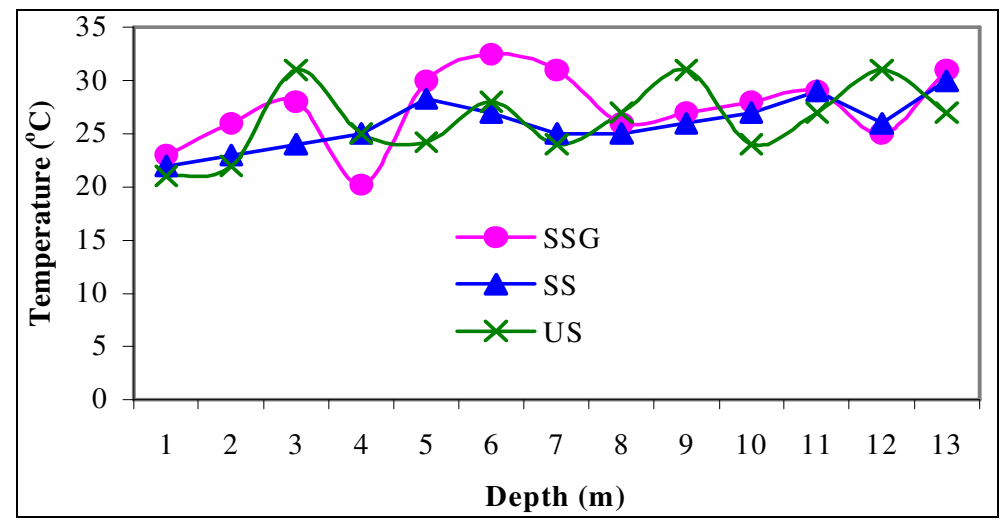

Figure 13: Comparison of experiments for saturated soil with groundwater flow (SSG), saturated soil without groundwater flow (SS) and unsaturated soil without groundwater flow (US).

$\delta \quad$ is volumetric specific heat ratio.

$\rho \quad$ is the density $\left(\mathrm{kg} \mathrm{m}^{-3}\right)$.

The experiments and calculations are conducted for unsaturated soil without groundwater flow (US), saturated soil without groundwater flow (SS) and saturated soil with groundwater flow (SSG) under same conditions and their results are compared with each other in Figures 10-13. 
Table 2: Comparison of energy costs between different energy sources

\begin{tabular}{ccc}
\hline Energy source & $\begin{array}{c}\text { Energy costs } \\
\text { (US } \mathbf{c / k W h})\end{array}$ & $\begin{array}{c}\text { Potential future } \\
\text { energy costs } \\
\text { (US } \mathbf{k} / \mathbf{k W h})\end{array}$ \\
\hline Hydro & $2-10$ & $2-8$ \\
Biomass & $5-15$ & $4-10$ \\
Geothermal & $2-10$ & $1-8$ \\
Wind & $5-13$ & $3-10$ \\
Solar & $25-125$ & $5-25$ \\
Tidal & $12-18$ & $4-10$ \\
Coal & 4 & 0.4 \\
\hline
\end{tabular}

Table 3: COPs for different loops

\begin{tabular}{lll}
\hline Type of system & $\mathrm{COP}_{\mathrm{C}}$ & $\mathrm{COP}_{\mathrm{H}}$ \\
\hline Opened loops & 4.75 at $15^{\circ} \mathrm{C}$ & 3.6 at $10^{\circ} \mathrm{C}$ \\
Closed loops & 3.93 at $25^{\circ} \mathrm{C}$ & 3.1 at $0{ }^{\circ} \mathrm{C}$ \\
Internal loops & 3.52 at $30^{\circ} \mathrm{C}$ & 4.2 at $20^{\circ} \mathrm{C}$ \\
\hline
\end{tabular}

The temperature in vertical boreholes used, as heat source for GSHPs will slowly drop with time, so more energy is extracted. This can be mitigated either by a deeper borehole (in a new installation) or a system to replenish the energy extracted from the hole (in both new and existing installations). Raising the brine temperature from $-5^{\circ} \mathrm{C}$ to $0^{\circ} \mathrm{C}$ may improve the COP by $10-50 \%$ depending on the type of heat pump.

\section{Performance Enhancement of GSHP}

The heat transfer between the GSHP and its surrounding soil is affected by a number of factors such as working fluid properties (e.g., 20\% glycol) and its flow conditions, soil thermal properties, soil moisture content and groundwater velocity and properties, etc. The GSHP has a great potential to be one of the main energy sources in the future as it can be tapped in a number of different ways and can be used to produce hot water as well as electricity. It has a large spatial distribution with almost all countries having at least low enthalpy resources available (less than $125^{\circ} \mathrm{C}$ ) and many countries around the world in both developing and developed countries are already harnessing it. It is a resource that has always been there and does not rely on specific factors such as the wind to be blowing or the sun to be shining, as is the case with other forms of renewable energies. The GSHP is inherently clean and environmentally sustainable and will soon become more economical than combustion (fossil fuel) plants as regulations on plant emission levels are tightened and expensive abatement measures such as carbon capture and storage become compulsory. This study urges the need for the GSHP to be considered much more strongly than it currently is in environmental policies as it has been overlooked as a main alternative to fossil fuels and other forms of renewable energies.

Geothermal power utilises the heat energy naturally produced within the earth. Its wide abundance and renewable nature make it an attractive alternative energy source to fossil fuels. The environmental impact of geothermal power plants is negligible in comparison to combustion plants and it is progressively becoming more financially viable as emission regulations are tightened. The technology is increasingly being utilised by countries all over the world, as there are many different ways in which geothermal energy can be harnessed. Geothermal power is very competitive with other sources of energy when it comes to energy costs. Table 2 shows the globally averaged energy costs in 2008 for different energy sources and shows what the potential future energy costs for different sources will be. As shown in table 3, geothermal is already generally more financially viable and cost-effective globally than other forms of renewable power, being on par with hydro-electricity (however, it is important to note that costs will vary between countries) (USEPA, 1997).

Over its first year of operation, the ground source heat pump system has provided $91.7 \%$ of the total heating requirement of the room and $55.3 \%$ of the domestic water-heating requirement, although only sized to meet half the design-heating load. The heat pump has operated reliably and its performance appears to be at least as good as its specification. The system has a measured annual performance factor of 3.16. The system is quiet and unobtrusive and achieved comfort levels. The heat pump does not reduce the useful space in the laboratory, and there are no visible signs of the installation externally (no flue, vents, etc.). The performance of the heat pump system could also be 
Table 4: Energy efficiency ratios for cooling and heating applications

\begin{tabular}{cccc}
\hline Application & Type of system & Minimum EER & Minimum COP \\
\hline Cooling & Opened loops $\left(10^{\circ} \mathrm{C}\right)$ & 13.0 & - \\
& Closed loops $\left(25^{\circ} \mathrm{C}\right)$ & 11.5 & - \\
\multirow{2}{*}{ Heating } & Opened loops $\left(10^{\circ} \mathrm{C}\right)$ & - & 3.1 \\
& Closed loops $\left(0^{\circ} \mathrm{C}\right)$ & - & 2.8 \\
\hline
\end{tabular}

Table 5: Direct expansion closed loop ground or water source heat pumps

\begin{tabular}{cccc}
\hline Application & Type of system & Minimum EER & Minimum COP \\
\hline Cooling & Opened loops $\left(10^{\circ} \mathrm{C}\right)$ & 11.0 & 3.2 \\
& Closed loops $\left(25^{\circ} \mathrm{C}\right)$ & 10.5 & 3.1 \\
\multirow{2}{*}{ Heating } & Opened loops $\left(10^{\circ} \mathrm{C}\right)$ & - & 3.0 \\
& Closed loops $\left(0^{\circ} \mathrm{C}\right)$ & - & 2.5 \\
\hline
\end{tabular}

Table 6: Key energy star criteria for ground-source heat pumps

\begin{tabular}{cccc}
\hline $\begin{array}{c}\text { Product } \\
\text { Type }\end{array}$ & $\begin{array}{c}\text { Minimum } \\
\text { EER }\end{array}$ & $\begin{array}{c}\text { Minimum } \\
\text { COP }\end{array}$ & $\begin{array}{c}\text { Water Heating } \\
\text { (WH) }\end{array}$ \\
\hline Closed-loop & 14.1 & 3.3 & Yes \\
With integrated WH & 14.1 & 3.3 & N/A \\
Open-loop & 16.2 & 3.6 & Yes \\
With integrated WH & 16.2 & 3.6 & N/A \\
DX & 15.0 & 3.5 & Yes \\
With integrated WH & 15.0 & 3.5 & N/A \\
\hline
\end{tabular}

improved by eliminating unnecessary running of the integral distribution pump. It is estimated that reducing the running time of this pump, which currently runs virtually continuously, would increase the overall performance factor to 3.43 . This would improve both the economical and the environmental performance of the system. More generally, there is still potential for improvement in the performance of heat pumps, and seasonal efficiencies for ground source heat pumps of 4.0 are already being achieved. It is also likely that the unit costs will fall as production volumes increase.

Energy Efficiency Ratio (EER) is a ratio calculated by dividing the cooling capacity in watts per hour by the power input in watts at any given set of rating conditions. Coefficient of performance (COP) is a ratio calculated for both the cooling $(\mathrm{C})$ and heating $(\mathrm{H})$ capacities by dividing the capacity expressed in watts by the power input in watts (excluding any supplementary heat). Table 3 summarises COP for different loops. Tables 4-5 present energy efficiency ratios for cooling and heating purposes.

Ground storage systems can be classified in many different ways. One of the most important classifications is in accordance to the temperature of the storage. The ground storage systems are classified as follows:
The GSHPs, without artificial charging the soil temperature about $10^{\circ} \mathrm{C}$.

Low temperature ground storage - temperature $<50^{\circ} \mathrm{C}$. High temperature ground storage - temperature $>50^{\circ} \mathrm{C}$. Table 6 shows COP and EER for different applications. Conserving natural resources benefits everyone now and into the future. For homebuilders, green building means the resource-efficient design, construction, and operation of homes. It represents an approach to both building and marketing homes that highlights environmental quality.

\section{Heat Exchanger Design}

A heat exchanger is usually referred to as a micro heat exchanger $(\mu \mathrm{HX})$ if the smallest dimension of the channels is at the micrometer scale, for example from 10 $\mu \mathrm{m}$ to $1 \mathrm{~mm}$. Beside the channel size, another important geometric characteristic is the surface area density $\rho$ $\left(\mathrm{m}^{2} / \mathrm{m}^{3}\right)$, which is defined as the ratio of heat exchange surface area to volume for one fluid. It reflects the compactness of a heat exchanger and provides a classification criterion of note that the two parameters, the channel size and surface area density, are interrelated, and the surface area density increases when 
the channel size decreases. The exchangers that have channels with characteristic dimensions of the order of $100 \mu \mathrm{m}$ are likely to get an area density over 10000 $\mathrm{m}^{2} / \mathrm{m}^{3}$ and usually referred to as $\mu \mathrm{HXs}$ (Allan, et al., 1999).

By introducing $\alpha$ in the specific heat exchanger performance equation, the volumetric heat transfer power $\mathrm{P} / \mathrm{V}\left(\mathrm{W} / \mathrm{m}^{3}\right)$ can be expressed as follows:

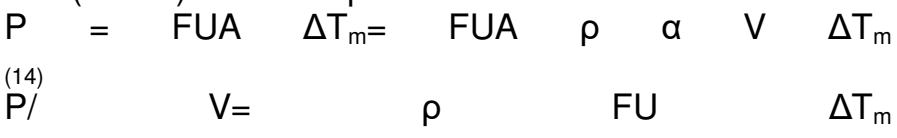

(15)

Where, $\mathrm{U}, \Delta \mathrm{T}_{\mathrm{m}}$ and $\mathrm{F}$ refer to the overall heat transfer coefficient $\left(\mathrm{W} / \mathrm{m}^{2} \mathrm{~K}\right)$, the mean temperature difference $(\mathrm{K})$ and the dimensionless mean temperature difference correction factor for flow configuration respectively. Note that for a specific heat exchanger performance, high values of $\alpha$ lead to a corresponding high volumetric heat transfer power, larger than that of the conventional equipment by several orders of magnitude. As a result, the heat exchanger design by miniaturisation technology has become a common research focus for process intensification (Philappacopoulus, et al., 2001).

The main advantages of the $\mu \mathrm{HX}$ design are its "compactness, effectiveness and dynamic". These properties enable an exact process control and intensification of heat and mass transfer (EPRI and NRECA, 1997):

\section{COMPACTNESS}

The high surface area density reduces substantially the volume of the heat exchanger needed for the same thermal power. As a result, the space and costly material associated with constructing and installing the heat exchanger could be reduced significantly. Moreover, the fluid holdup is small in a $\mu \mathrm{HX}$; this is important for security and economic reasons when expensive, toxic, or explosive fluids are involved.

\section{EFFECTIVENESS}

The relatively enormous overall heat transfer coefficient of the $\mu \mathrm{HXs}$ makes the heat exchange procedure much more effective. In addition, the development of microfabrication techniques (McCray, 1997) such as LIGA, stereolithography, laser beam machining, and electroformation allows designing a $\mu \mathrm{HX}$ with more effective configurations and high pressure resistance.

\section{Dynamic}

The quick response time of a $\mu \mathrm{HX}$ provides a better temperature control for relatively small temperature differences between fluid flows. The quick response (small time constant) is connected to the small inertia of the heat transfer interface (the small metal thickness that separates the two fluids). On the other hand, the exchanger as a whole, including the "peripheric" material, usually has a greater inertia than conventional exchangers, entailing a large time-constant. Thus the response of one fluid to a temperature change of the other fluid comprises two "temperature-change waves", with very distinct time-constants. In conventional exchangers, it is possible that the two responses are blurred into one.

However, the $\mu \mathrm{HXs}$ on one hand, the high performance is counterbalanced by a high pressure drop, a rather weak temperature jump and an extremely short residence time. On the other hand, those fine channels $(\sim 100 \mu \mathrm{m})$ are sensitive to corrosion, roughness and fouling of the surfaces. Moreover, the distinguishing feature of the $\mu \mathrm{HXs}$ is their enormous volumetric heat exchange capability accompanied with some difficulties in achievement realisation. The $\mu \mathrm{HXs}$ design optimisation lies, on one hand, in maximising the heat transfer in a given volume taking place principally in microchannels, while, on the other hand, minimising the total pressure drops, the dissipations, or the entropy generation when they function as a whole system. Moreover, difficulties such as the connection, assembly, and uniform fluid distribution always exist, all of which should be taken into account at the design stage of the $\mu \mathrm{HXs}$. All these make the optimisation of the $\mu \mathrm{HXs}$ design a multi-objective problem, which calls for the introduction of multi-scale optimisation method (Jo, et al., 2001) to bridge the microscopic world and the macroscopic world. In recent years, the fractal theory (Anandarajah, 2003) and constructal theory (Petrov, et al., 1997) have been introduced to bridge the characteristics of heat and mass transfer that mainly takes place at the micro-scale and the global performance of the heat exchanger system (Fahlen, 1997).

The concept of multi-scale heat exchanger is expected to have the following characteristics (Rafferty, 2003):

A relatively significant specific heat exchange surface compared to that of traditional exchangers;

A high heat transfer coefficient, as heat transfer takes place at micro-scales and meso-scales;

An optimised pressure drop equally distributed between the various scales;

A modular character, allowing assembly of a macro-scale exchanger from microstructured modules.

Some difficulties still exist. On one hand, the properties of flow distribution in such an exchanger are still unknown (Smith, et al., 1999). A lot of research work still needs to be done for the equidistribution optimisation. On the other hand, 3-D modelling of heat transfer for such an exchanger requires a thorough knowledge of the hydrodynamics and profound studies on elementary volume (smallest scale micro channels). Finally, 


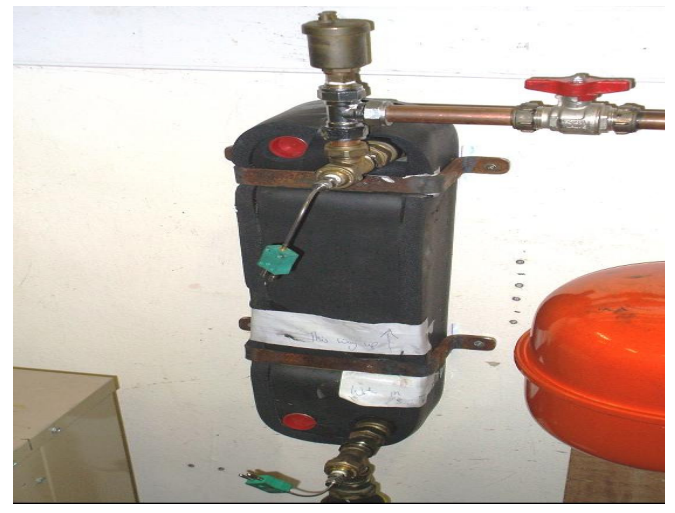

Figure 14:The heat exchanger.

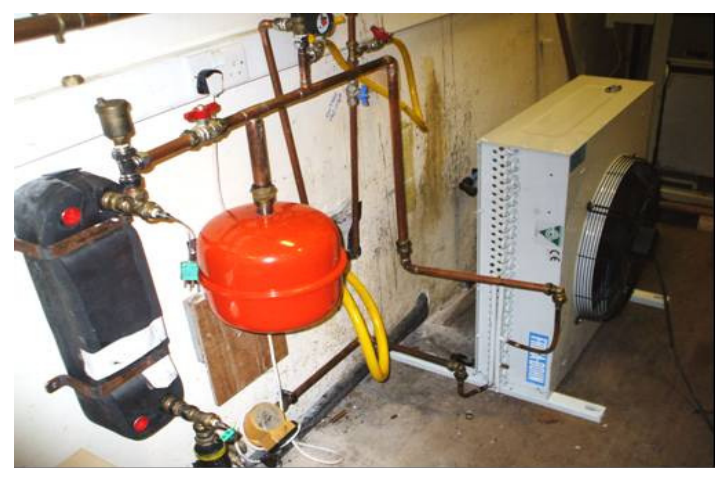

Figure 15: The connections of the heat exchanger, water pump, heat rejection fan and expansion valve.

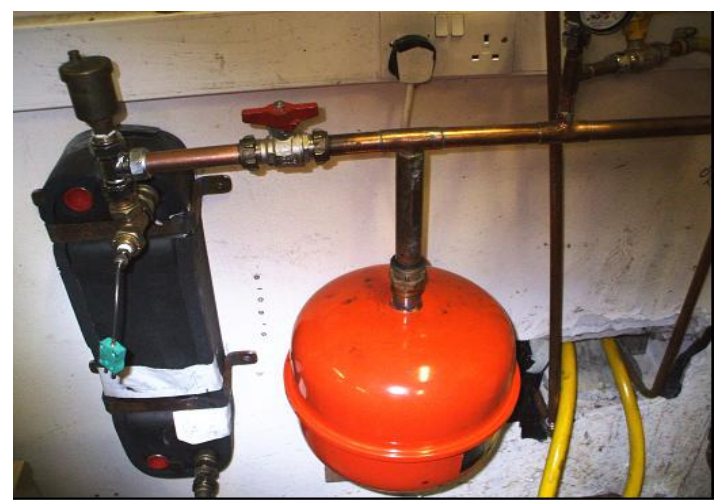

Figure 16: The connections of the heat exchanger and expansion valve.

maintenance problems for this type of integrated structures may become unmanageable when fouling; corrosion, deposits or other internal perturbations are to be expected. Figures 14-16 show the connections of the heat exchanger, water pump, heat rejection fan and expansion valve.

The present DX GSHP system has been designed taking into account the local meteorological and geological conditions and then systems was installed, using the ground source as a heat source. This project yielded considerable experience and performance data for the novel methods used to exchange heat with the primary effluent.

The heat pump have also fitted in dry, well-ventilated position where full access for service was possible and monitored the performance of a number of the DX 


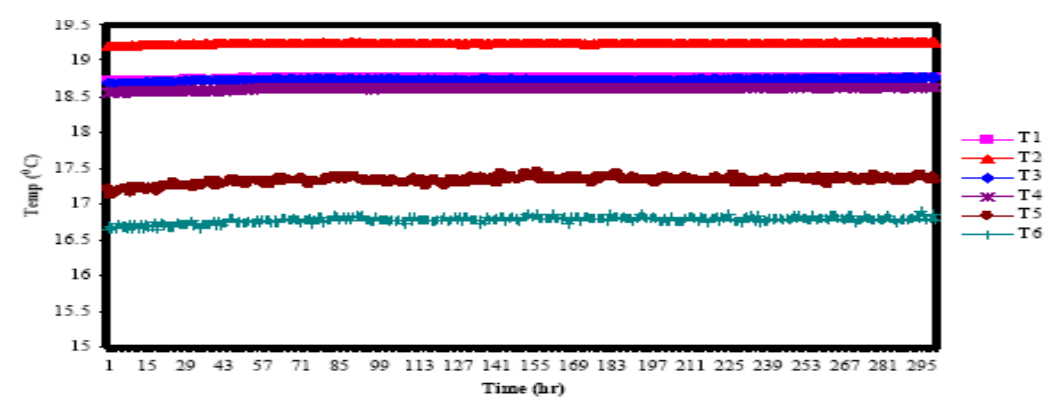

Figure 17: Variation of temperatures for heat exchanger for two weeks.

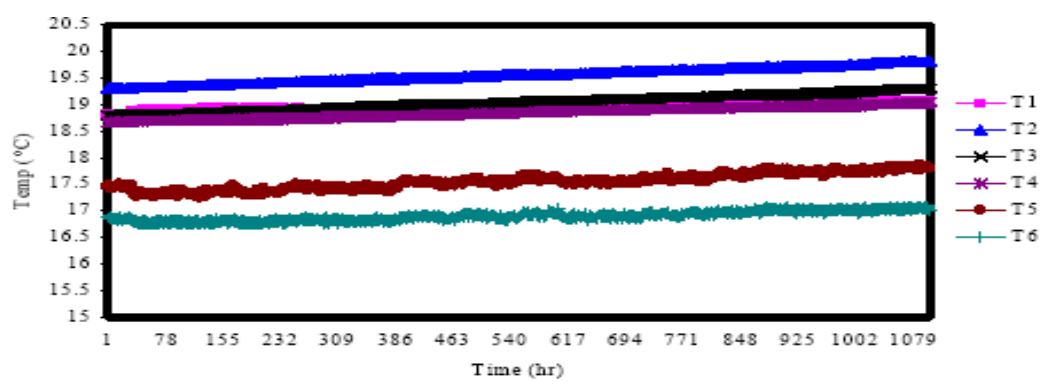

Figure 18: Variation of temperatures for heat exchanger for 45 days.

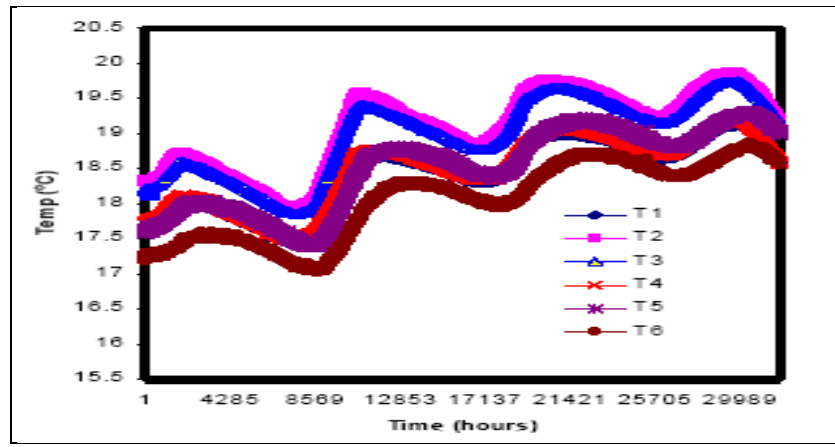

Figure 19: Variation of temperatures for heat exchanger for year.

GSHPs, including one so-called "hybrid" system that included both ground-coupling and a cooling tower.

The GSHPs provide an effective and clean way of heating buildings worldwide. They make use of renewable energy stored in the ground, providing one of the most energy-efficient ways of heating buildings. They are suitable for a wide variety of building types and are particularly appropriate for low environmental impact projects. They do not require hot rocks (geothermal energy) and can be installed in most of the world, using a borehole or shallow trenches or, less commonly, by extracting heat from a pond or lake. Heat collecting pipes in a closed loop, containing water (with a little antifreeze) are used to extract this stored energy, which can then be used to provide space heating and domestic hot water. In some applications, the pump can be reversed in summer to provide an element of cooling. The only energy used by the GSHP systems is electricity to power the pumps. Typically, a GSHP will deliver three or four times as much thermal energy (heat) as is used in electrical energy to drive the system. For a particularly environmental solution, green electricity can be purchased. The GSHP systems have been widely used in other parts of the world, including North America and Europe, for many years. Typically they cost more to install than conventional systems; however, they have very low maintenance costs and can be expected to provide reliable and environmentally friendly heating for in excess of 20 years. Ground source heat pumps work best with heating systems, which are optimised to run at a lower water temperature than is commonly used in the UK boiler and radiator systems. As such, they make an ideal partner for underfloor heating systems. Figures 17-19 show daily system temperatures for a sample day in each 


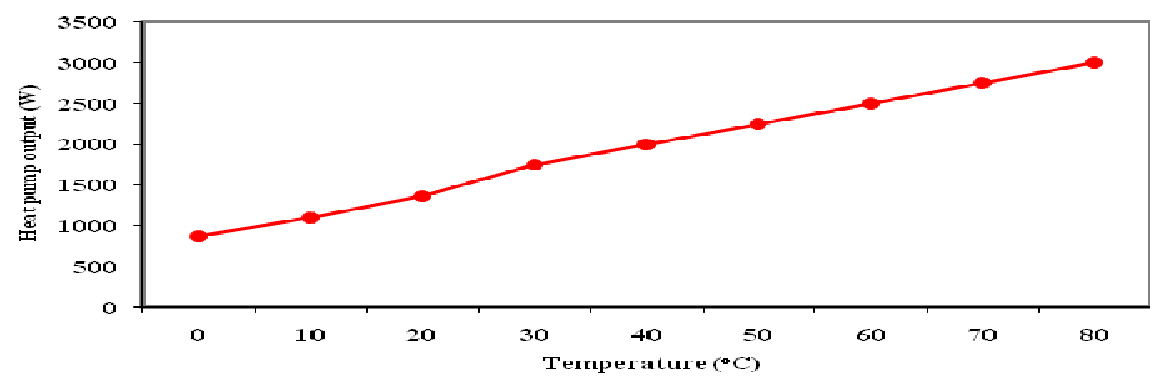

Figure 20: Variation of heat pump output with temperature

period and the periods of operation of the auxiliary heater and the immersion heater. The performance of the heat pump is inversely proportional to the difference between the condensation temperature and the evaporation temperature (the temperature lift). Figure 20 shows the output of the heat pump for a range of output (condensation) temperatures. These are stable operating conditions, but not true steady state conditions.

At output temperatures greater than $40^{\circ} \mathrm{C}$, the heat pump was providing heating to the domestic hot water. The scatter in the points is largely due to variations in the source temperatures (range $0.2^{\circ} \mathrm{C}$ to $4.3^{\circ} \mathrm{C}$ ). These results indicate that the system performance meets and possibly exceeds the specified rating for the heat pump of $3.7 \mathrm{~kW}$ at an output temperature of $45^{\circ} \mathrm{C}$. Two different control mechanisms for the supply of energy from the heat pump for space heating were tested.

From March 2007 until July 2008, the supply of energy from the heat pump to the space heating system was controlled by a thermostat mounted in the room. From August 2008, an alternative control using an outside air temperature sensor was used. This resulted in the heat pump operating more continuously in cold weather and in reducing the use of the auxiliary heater considerably. The amount the auxiliary heater is used has a large effect on the economic performance of the system. Using the outdoor air temperature sensor results in the adjustment of the return temperature being for changes in the outdoor temperature and a good prediction of the heating requirement.

Very stable internal temperatures were maintained. Figure 20 shows the daily total space heating from the heat pump and the auxiliary heater for the two heating control systems. The same period of the year has been compared, using the room temperature sensor and an outdoor air temperature sensor. The operating conditions were not identical, but the average 24-hour temperatures for the two periods were quite similar at $9.26^{\circ} \mathrm{C}$ and $9.02^{\circ} \mathrm{C}$ respectively.

$\mathrm{T} 1$ is the Heat exchanger temperature

T2 is the compressor temperature

$\mathrm{T} 3$ is the condenser temperature

T4 is the vapour temperature

$\mathrm{T} 5$ is the indoor temperature
T6 is the pit temperature

\section{Performance of the Ground Collector}

The flow rate in the ground coil is $0.23 \mathrm{l} / \mathrm{s}$. The heat collection rate varies from approximately $19 \mathrm{~W}$ to $27 \mathrm{~W}$ per meter length of collector coil. In winter, the ground coil typically operates with a temperature differential of about $5^{\circ} \mathrm{C}$ (i.e., a flow temperature from the ground of $2^{\circ} \mathrm{C}$ to $3^{\circ} \mathrm{C}$ and a return temperature to the ground coil of $-1^{\circ} \mathrm{C}$ to $-2^{\circ} \mathrm{C}$ ). Icing up of the return pipework immediately below the heat pump can be quite severe. The ground coil temperatures are considerably higher in summer when, for water heating, the temperature differential is similar but flow and return temperatures are typically $11^{\circ} \mathrm{C}$ and $6^{\circ} \mathrm{C}$ respectively. When the heat pump starts, the flow and return temperatures stabilise very quickly. Even over sustained periods of continuous operation the temperatures remained stable. The ground coil appears adequately sized and could possibly be oversized. Figure 20 shows the variation of ground source heat pump against ground temperatures.

A residential GSHP system is more expensive to install than a conventional heating system. It is most costeffective when operated year-round for both heating and cooling. In such cases, the incremental payback period can be as short as 3-5 years. A GSHP for a new residence will cost around $9-12 \%$ of the home construction costs. A typical forced air furnace with flex ducting system will cost $5-6 \%$ of the home construction costs. Stated in an alternative form, the complete cost of a residential GSHP system is $\$ 3,500-\$ 5,500$ per ton. Horizontal loop installations will generally cost less than vertical bores. For a heating dominated residence, figure around 550 square feet/ton to size the unit. A cooling dominated residence would be estimated around 450 square feet/ton. The Table 3 compares three types of systems.

\section{Geothermal Energy}

Electricity Generation and Direct Use at the End 2008 Concerning direct heat uses, Table 7 shows that the 
Table 7: Geothermal Energy: Electricity Generation and Direct Use at the End 2008 (Knoblich, et al., 1993)

\begin{tabular}{|c|c|c|c|c|c|c|}
\hline \multirow[t]{2}{*}{ Regions } & \multicolumn{3}{|c|}{ Electricity generation } & \multicolumn{3}{|c|}{ Direct use } \\
\hline & 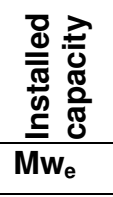 & 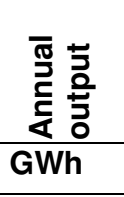 & 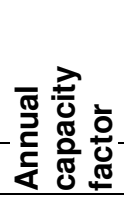 & 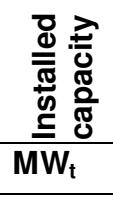 & 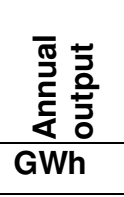 & 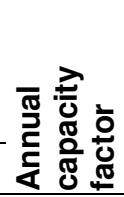 \\
\hline Algeria & & & & 100 & 441 & 0.50 \\
\hline Ethiopia & 9 & 30 & 0.40 & & & \\
\hline Kenya & 45 & 390 & 0.99 & 1 & 3 & 0.25 \\
\hline Tunisia & & & & 20 & 48 & 0.28 \\
\hline Total Africa & 54 & 420 & 0.89 & 121 & 492 & 0.46 \\
\hline Canada & & & & 378 & 284 & 0.09 \\
\hline Costa Rica & 115 & 804 & 0.80 & & & \\
\hline El Salvador & 161 & 552 & 0.39 & & & \\
\hline Guadeloupe & 4 & 25 & 0.67 & & & \\
\hline Guatemala & 33 & 216 & 0.74 & 3 & 30 & 1.00 \\
\hline Honduras & & & & 1 & 5 & 0.76 \\
\hline Mexico & 750 & 5642 & 0.86 & 164 & 1089 & 0.76 \\
\hline Nicaragua & 70 & 583 & 0.95 & & & \\
\hline $\begin{array}{l}\text { United States of } \\
\text { America }\end{array}$ & 2228 & 16813 & 0.86 & 5366 & 5640 & 0.12 \\
\hline Venezuela & & & & 1 & 4 & 0.63 \\
\hline Total North America & 3361 & 24635 & 0.84 & 5913 & 7052 & 0.14 \\
\hline Argentina & 1 & N.A & 0.67 & 26 & 125 & 0.55 \\
\hline Chile & & & & N.A & 2 & 0.55 \\
\hline Colombia & & & & 13 & 74 & 0.63 \\
\hline Peru & & & & 2 & 14 & 0.65 \\
\hline Total South America & 1 & N.A & 0.67 & 41 & 215 & 0.60 \\
\hline China & 29 & 100 & 0.39 & 2814 & 8724 & 0.35 \\
\hline Georgia & & & & 250 & 1752 & 0.80 \\
\hline India & & & & 80 & 699 & 1.00 \\
\hline Indonesia & 590 & 4575 & 0.89 & 7 & 12 & 0.19 \\
\hline Japan & 547 & 3451 & 0.72 & 258 & 1621 & 0.72 \\
\hline Korea (Republic) & & & & 51 & 299 & 0.67 \\
\hline Nepal & & & & 1 & 6 & 0.66 \\
\hline Philippines & 1863 & 10594 & 0.65 & 1 & 7 & 0.79 \\
\hline Thailand & N.A & 1 & 0.38 & 1 & 4 & 0.68 \\
\hline Turkey & 15 & 81 & 0.62 & 820 & 4377 & 0.61 \\
\hline Total Asia & 3044 & 18802 & 0.71 & 4283 & 17501 & 0.47 \\
\hline Austria & & & & 255 & 447 & 0.20 \\
\hline Belgium & & & & 4 & 30 & 0.87 \\
\hline Bulgaria & & & & 107 & 455 & 0.48 \\
\hline Croatia & & & & 114 & 153 & 0.15 \\
\hline Czech Republic & & & & 13 & 36 & 0.33 \\
\hline Denmark & & & & 3 & 15 & 0.52 \\
\hline Finland & & & & 81 & 167 & 0.24 \\
\hline FYR Macedonia & & & & 81 & 142 & 0.20 \\
\hline France & & & & 326 & 1365 & 0.48 \\
\hline Germany & & & & 397 & 436 & 0.13 \\
\hline Greece & & & & 57 & 107 & 0.21 \\
\hline Hungary & & & & 328 & 1400 & 0.49 \\
\hline Iceland & 170 & 1138 & 0.76 & 1469 & 5603 & 0.44 \\
\hline Italy & 621 & 4403 & 0.81 & 680 & 2500 & 0.42 \\
\hline Lithuania & & & & 21 & 166 & 0.90 \\
\hline
\end{tabular}


Table 7. Continued

\begin{tabular}{|c|c|c|c|c|c|c|}
\hline Netherlands & & & & 11 & 16 & 0.17 \\
\hline Norway & & & & 6 & 9 & 0.17 \\
\hline Poland & & & & 69 & 76 & 0.13 \\
\hline Portugal & 20 & 79 & 0.45 & 6 & 10 & 0.20 \\
\hline Romania & & & & 110 & 120 & 0.12 \\
\hline Russian Federation & 23 & 85 & 0.42 & 307 & 1703 & 0.63 \\
\hline Serbia and Montenegro & & & & 80 & 660 & 0.94 \\
\hline Slovakia & & & & 132 & 588 & 0.51 \\
\hline Slovenia & & & & 103 & 300 & 0.33 \\
\hline Spain & & & & 70 & 292 & 0.47 \\
\hline Sweden & & & & 377 & 1147 & 0.35 \\
\hline Switzerland & & & & 547 & 663 & 0.14 \\
\hline United Kingdom & & & & 3 & 10 & 0.38 \\
\hline Total Europe & 834 & 5705 & 0.78 & 5757 & 18616 & 0.37 \\
\hline Israel & & & & 63 & 476 & 0.86 \\
\hline Jordan & & & & 153 & 428 & 0.32 \\
\hline Total Middle East & & & & 216 & 904 & 0.48 \\
\hline Australia & N.A & 1 & 0.60 & 10 & 82 & 0.90 \\
\hline New Zealand & 410 & 2323 & 0.65 & 308 & 1967 & 0.73 \\
\hline Total Oceania & 410 & 2324 & 0.65 & 318 & 2049 & 0.74 \\
\hline TOTAL WORLD & 7704 & 51886 & 0.77 & 16649 & 46829 & 0.32 \\
\hline
\end{tabular}

three countries with the largest amount of installed power: USA $\left(5,366 \mathrm{MW}_{\mathrm{t}}\right)$, China $\left(2,814 \mathrm{MW}_{\mathrm{t}}\right)$ and Iceland $\left(1,469 \mathrm{MW}_{\mathrm{t}}\right)$ cover $58 \%$ of the world capacity, which has reached $16,649 \mathrm{MW}_{\mathrm{t}}$, enough to provide heat for over 3 million houses (USGAO, 1994).

Out of about 60 countries with direct heat plants, beside the three above-mentioned nations, Turkey, several European countries, Canada, Japan and New Zealand have sizeable capacity.

The GSHPs energy cost savings vary with the electric rates, climate loads, soil conditions, and other factors. In residential building applications, typical annual energy savings are in the range of 30 to 60 percent compared to conventional HVAC equipment.

Most systems have less than $15 \mathrm{kWth}$ heating output, and with ground as heat source, direct expansion systems are predominant. Ground-source heat pumps had a market share of 95\% in 2006 (Rybach, et al., 1995) (Figure 21). Figure 22 illustrates the monthly energy consumption for a typical household in the United Kingdom. Unlike air source units, GSHP systems do not need defrost cycles nor expensive backup electric resistance heat at low outdoor air temperatures. The stable temperature of a ground source is a tremendous benefit to the longevity and efficiency of the compressor.

The energy used to operate this pump could be reduced if it were controlled to operate only when the heat pump was supplying heat. The improvement in efficiency would be greatest in summer when the heat pump is only operating for a short period each day. If this pump were controlled to operate only when the heat pump is operating, it is estimated that the overall annual performance factor of the heat pump system would be 3.43 , and that the average system efficiencies for the period November to March and April to September would be 3.42 and 3.44 respectively (Rybach, et al., 1997).

Under these conditions, it is predicted that there would only be a small variation in the efficiency of the heat pump system between summer and winter. This is explained by the fact that although the output temperature required for domestic water heating is higher than that required for space heating, the ground temperatures are significantly higher in the summer than in the winter.

There is clearly a lot more that must be done to support distribution GSHPs in general especially from the perspective of buildings in the planning and operation, and distribution GSHP systems (Figures 23-25).

\section{Applications of Geoexchanger systems}

Geoexchanger energy is a natural resource, which can be used in conjunction with heat pumps to provide energy for heating and hot water. $\mathrm{CO}_{2}$ emissions are much lower than gas fired boilers or electric heating systems. Geothermal heating is more expensive to install initially, than electrical or gas fired heating systems. However it is cheaper to run, has lower maintenance costs, and is cleaner in use than other sources of heating.

The temperature of the earth under 2 metres of the surface is a fairly constant $10^{\circ} \mathrm{C}$ throughout the year. At a 


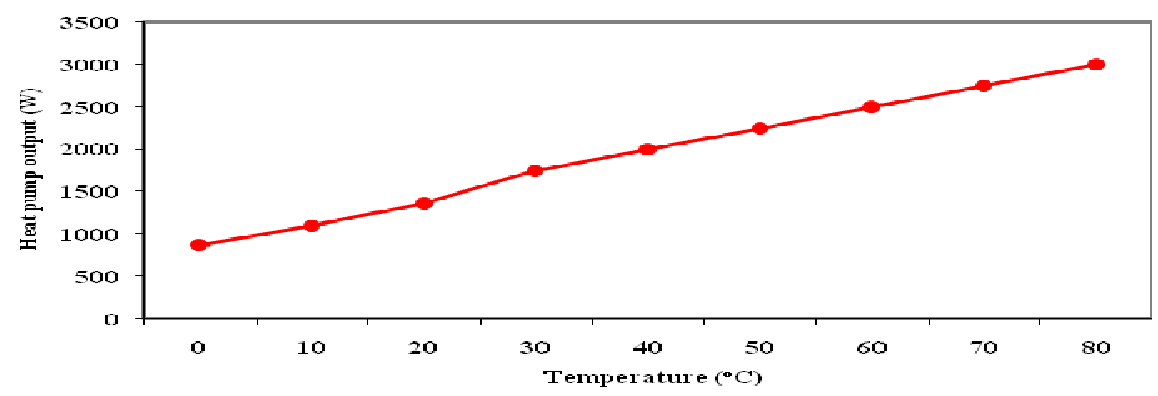

Figure 20: Variation of heat pump output with temperature

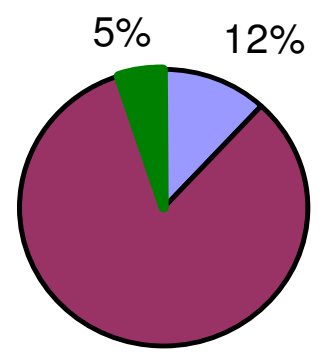

$83 \%$ $\square$ Groundwater

$\square$ Ground (loops, BHE)

Air

Figure 21: Distribution of heat sources for heat pumps (for space heating).

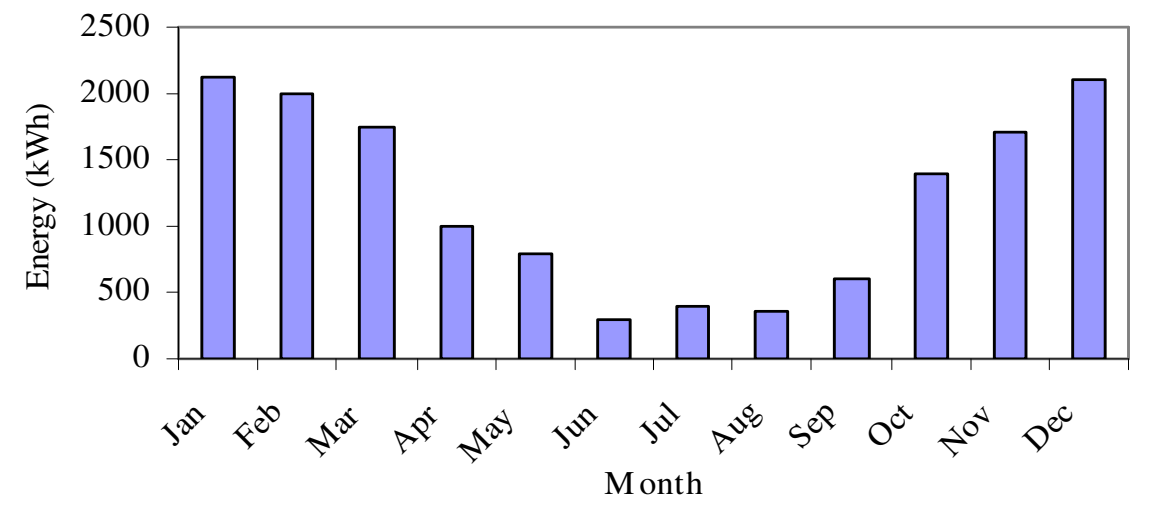

Figure 22: Monthly heating energy demands.

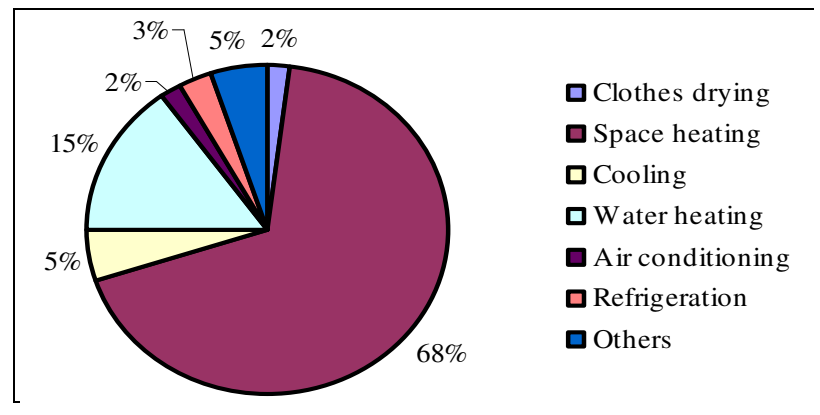

Figure 23. Residential energy consumptions according to end use. 


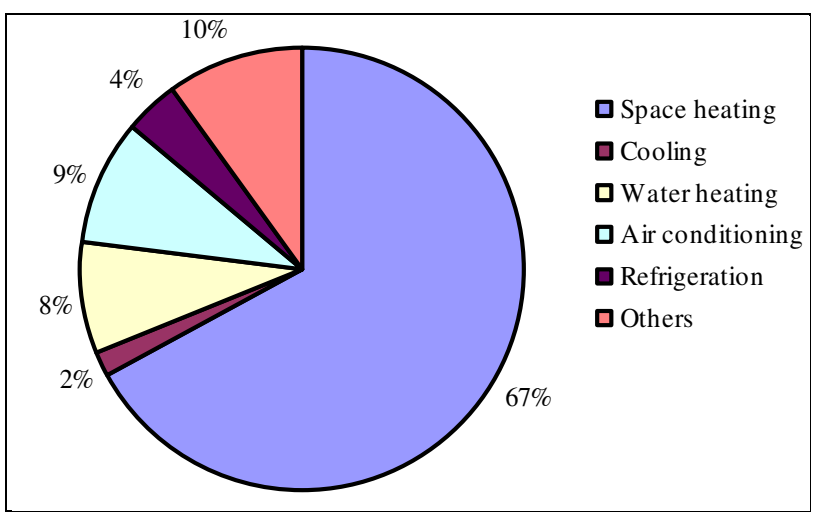

Figure 24. Commercial energy consumptions according to end use.

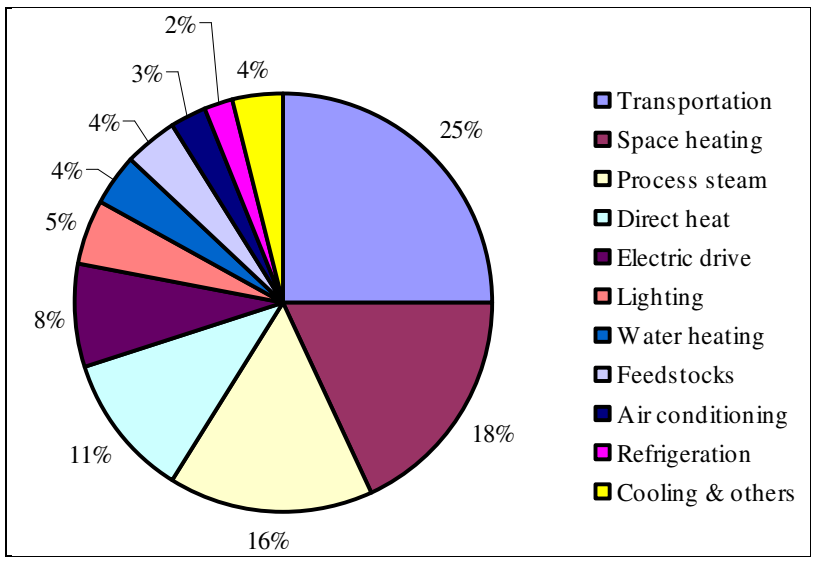

Figure 25: Energy consumptions according to end use.

depth of about 100 metres, the temperature of any water or rock is at about $12^{\circ} \mathrm{C}$ throughout the year. The heat stored at this depth comes largely from the sun, the earth acting as a large solar collector. For very deep wells, in excess of about 170 metres, there is an added component of heat from the core of the earth. As an approximation, one can add $3^{\circ} \mathrm{C}$ of heat gain for every 100 metres of depth drilled into the earth.

A closed loop system takes the heat gained from the bedrock itself. In a vertical system a borehole of a diameter of about $150 \mathrm{~mm}$ is drilled, depth varies between 32 and 180 metres but will depend on the energy requirements. Multiple boreholes can be drilled. A pair of pipes with a special U-bend assembly at the bottom is inserted into the borehole and the void between pipe and hole backfilled with a special grout solution so that the pipe is in close contact with the rock strata or earth. Fluid (referred to as 'brine' is then circulated through this loop and is heated up by the bedrock. Different rock types will give different results. In some cases a number of boreholes will be made (for example, over a car park) to provide sufficient energy for the heat pump supply. If the ground is not suitable, horizontal loops can be laid or even trench filled 'slinky' loops, which are very simple to install. However trench filled systems and horizontal systems require much more ground than vertical systems. If one has a pond or lake nearby then can lay a closed loop at the base of the pond (it needs to be about 2 metres deep), or simply extract the water directly out of the lake at low level and re-distribute it elsewhere in the lake.

Heat pumps can be cheaper to operate than other heating systems because, by tapping into free heat in the outdoor air, ground or water supply, they give back more energy-in the form of heat-than the equivalent amount of electrical energy they consume.

For example, in a heating mode, a highly efficient heat pump could extract energy from the earth and transfer it into a building. For every $1 \mathrm{KWh}$ of electrical energy used to drive the heat pump, around 3 to $4 \mathrm{kWh}$ of thermal energy will be produced. In a cooling mode, the heat pump works in reverse and heat can be extracted from a building and dissipated into the earth. Heat pumps which work in a heating mode are given a 'coefficient of performance' or 'COP' calculated by dividing the input $\mathrm{kWh}$ into the output $\mathrm{kWh}$. This will give a COP figure, which varies with the input temperature and is the ratio of energy in to energy out. In a cooling mode, the ratio is 
called the 'energy efficiency ratio' or 'EER'. The higher the EER and COP ratios are, the more efficient the unit will be. Geothermal/GSHPs are self-contained systems. The heat pump unit is housed entirely within the building and connected to the outside-buried ground loop.

Conventional heating or cooling systems require energy from limited resources, e.g., electricity and natural gas, which have become increasingly more expensive and are at times subjects to shortages. Much attention has been given to sources that exist naturally and can be exploited as a natural phenomenon or what is known as renewable energy. Such energy includes geothermal energy, solar energy, tidal energy, and wind generated energy.

While all of these energy sources have advantages and disadvantages, geothermal energy, i.e., energy derived from the earth or ground, has been considered by many as the most reliable, readily available, and most easily tapped of the natural phenomena.

This study has dealt with the modelling of vertical closedloop and ground source heat pump system. The challenges associated with the design of these systems originate from the fact that they present a unique type of heat transfer problem. First, there are inherent inabilities to make direct observations in the subsurface environment with respect to both space and time. Second, heat transfer within the subsurface environment can be highly transient. Consequently, a considerable amount of research in the past decade has been geared towards optimising the design and performance of GSHP systems and this study is part of those efforts.

The installation and operation of a geothermal system may be affected by various factors. These include, but are not limited to, the field size, the hydrology of the site the thermal conductivity and thermal diffusivity of the rock formation, the number of wells, the distribution pattern of the wells, the drilled depth of each well, and the building load profiles.

The performance of the heat pump system could also be improved by eliminating unnecessary running of the integral distribution pump. This would improve both the economic and the environmental performance of the system.

The results of soil properties investigation have also demonstrated that the moisture content of the soil has a significant effect on its thermal properties. When water replaces the air between particles it reduces the contact resistance. Consequently, the thermal conductivity varied from $0.25 \mathrm{~W} / \mathrm{m} / \mathrm{K}$ for dry soil to $2.5 \mathrm{~W} / \mathrm{m} / \mathrm{K}$ for wet soil. However, the thermal conductivity was relatively constant above a specific moisture threshold. In fact, where the water table is high and cooling loads are moderate, the moisture content is unlikely to drop below the critical level. In Nottingham, where the present study was conducted, soils are likely to be damp for much of the time. Hence, thermal instability is unlikely to be a problem. Nevertheless, when heat is extracted, there will be a migration of moisture by diffusion towards the heat exchanger and hence the thermal conductivity will increase.

\section{CONCLUSION}

The direct expansion (DX) ground source heat pump (GSHP) systems have been identified as one of the best sustainable energy technologies for space heating and cooling in residential and commercial buildings. The GSHPs for building heating and cooling are extendable to more comprehensive applications and can be combined with the ground heat exchanger in foundation piles as well as seasonal thermal energy storage from solar thermal collectors.

Heat pump technology can be used for heating only, or for cooling only, or be 'reversible' and used for heating and cooling depending on the demand. Reversible heat pumps generally have lower COPs than heating only heat pumps. They will, therefore, result in higher running costs and emissions and are not recommended as an energyefficient heating option. The GSHP system can provide $91.7 \%$ of the total heating requirement of the building and $55.3 \%$ of the domestic water-heating requirement, although only sized to meet half the design-heating load. The heat pump can operate reliably and its performance appears to be at least as good as its specification. The system has a measured annual performance factor of 3.16. The heat pump system for domestic applications could be mounted in a cupboard under the stairs and does not reduce the useful space in the house, and there are no visible signs of the installation externally (no flue, vents, etc.).

The performance of the heat pump system could also be improved by eliminating unnecessary running of the integral distribution pump. It is estimated that reducing the running time of the pump, which currently runs virtually continuously, would increase the overall performance factor to 3.43 . This would improve both the economic and the environmental performance of the system. More generally, there is still potential for improvement in the performance of heat pumps, and seasonal efficiencies for ground source heat pumps of 4.0 are being achieved. It is also likely that the unit costs will fall as production volumes increase. By comparison, there is little scope to further improve the efficiency of gas- or oil-fired boilers.

\section{REFERENCES}

Allan ML, Philappacopoulus AJ (1999). Ground water protection issues with geothermal heat pumps. Geothermal Resources Council Transactions, 23, 101-105.

Anandarajah A (2003). Mechanism controlling permeability changes in clays due to changes in pore fluids. Journal of Geotechnical and Geoenvironmental Engineering, 129(2), 163-172.

ASHRAE (1995). Commercial/Institutional Ground Source Heat Pump 
Engineering Manual. American Society of heating, Refrigeration and Air-conditioning Engineers, Inc. Atlanta, GA: USA.

Bejan A (2000). Shape and Structure, from Engineering to Nature. Cambridge University Press: London. The many faces of proteaseprotein inhibitor interaction. EMBO J. 7, 1303-1130. 2000.

Bergles AE (1988). Some perspectives on enhanced heat transfer second generation heat transfer technology. Journal of Heat Transfer, 110, 1082-1096.

Bowman WJ, Maynes D (2001). A Review of Micro-Heat Exchangers Flow Physics, Fabrication Methods and Application. Proc. ASME IMECE, New York, USA, HTD-24280.

EPRI and NRECA (1997). Grouting for vertical geothermal heat pump systems: Engineering design and field procedures manual. Electric Power Research Institute TR-109169, Palo Alto, CA, and National Rural Electric Cooperative Association, Arlington, VA.

Fahlen, Per. (1997). Cost-effective heat pumps for Nordic countries, and heat pumps in cold climates. The 3rd International Conference, Acadia University, Wolfville, Canada. 1997.

Fridleifsson IB (2003). Status of geothermal energy amongst the world's energy sources. Geothermics, 30, 1-27.

Jo HY, Katsumi T, Benson CH, Edil TB (2001). Hydraulic conductivity and swelling of nonprehydrated GCLs permeated with single-species salt solutions. Journal of Geotechnical and Geoenvironmental Engineering, 127(7), 557-567.

Kalbus E, Reinstrof F, Schirmer M (2006). Measuring methods for groundwater surface water interactions: a review. Hydrology and Earth System Sciences, Vol. (10), pp. 873-887.

Knoblich K, Sanner B, Klugescheid M (1993). Ground source heat pumps. Giessener Geologische Schriften, 49, pp. 192, Giessen.

Li J, Zhang J, Ge W, Liu X (2004). Multi-scale methodology for complex systems. Chemical Engineering Science, 59, 1687-1700.

Luo L, Tondeur D (2005). Multiscale optimisation of flow distribution by constructal approach. Particuology, 3, 329-336.

Luo L, Tondeur D, Le Gall H, Corbel S (2007). Constructal approach and multi- scale components. Applied Thermal Engineering, 27, 1708-1714.

Luo L, Fan Y, Tondeur D (2007). Heat exchanger: from micro to multiscale design optimisation, International Journal of Energy Research, 31, 1266-1274.

Mandelbrot B (1982). The Fractal Geometry of Nature, 2nd Ed., W. H. Freeman, San Francisco, California.

McCray KB (1997). Guidelines for the construction of vertical boreholes for closed loop heat pump systems. Westerville, $\mathrm{OH}$, National Ground Water Association, pp. 43.

Petrov RJ, Rowe RK, Quigley RM (1997). Selected factors influencing GCL hydraulic conductivity, Journal of Geotechnical and Geoenvironmental Engineering, 123(8): 683-695.
Philappacopoulus AJ, Berndt, M. L. (2001). Influence of debonding in ground heat exchangers used with geothermal heat pumps. Geothermics, 30(5), 527-545.

Rafferty K (2003). Why do we need thermally enhanced fill materials in boreholes? National Ground Water Association.

Ramshaw C (1995). Process Intensification in the Chemical Industry, Mechanical Engineering Publications Ltd, London.

Rybach L, Hopkirk R (1995). Shallow and Deep Borehole Heat Exchangers - Achievements and Prospects. Pro. World Geothermal Congress 1995: 2133-2139.

Rybach L, Eugster WJ (1997). Borehole Heat Exchangers to Tap Shallow Geothermal Resources: The Swiss Success Story. In: S. F. Simmons, O. E.

Shah RK (1991). Compact Heat Exchanger Technology and Applications, in Heat Exchange Engineering, Volume 2, Compact Heat Exchangers: Techniques of Size Reduction, eds. E. A. Foumeny and P. J. Heggs, pp. 1-23, Ellis Horwood Limited, London.

Smith MD, Perry RL (1999). Borehole grouting: Field studies and therm performance testing. ASHRAE Transactions, 105(1), 451-457.

USEPA (1997). A short primer and environmental guidance for geothermal heat pumps. U.S.A Environmental Protection Agency EPA 430-K-97-007, pp. 9.

USGAO (1994). Geothermal energy: outlook limited for some uses but promising for geothermal heat pumps, USA General Accounting Office RECD-94-84. 